\title{
CORRECTION OF INSPECTION DATA FOR PART MISALIGNMENT UTILIZING A SMALL COMPUTER
}

\section{UNION CARBIDE CORPORATION}

\section{NUCLEAR DIVISION \\ OAK RIDGE Y-12 PLANT}

operated for the ATOMIC ENERGY COMMISSION under U. S. GOVERNMENT Contract W-7405 eng 26

UNION

CARBIDE
OAK RIDGE Y-12 PLANT

P. O. BOX Y

OAK RIDGE, TENNESSEE 37830 


\section{DISCLAIMER}

This report was prepared as an account of work sponsored by an agency of the United States Government. Neither the United States Government nor any agency Thereof, nor any of their employees, makes any warranty, express or implied, or assumes any legal liability or responsibility for the accuracy, completeness, or usefulness of any information, apparatus, product, or process disclosed, or represents that its use would not infringe privately owned rights. Reference herein to any specific commercial product, process, or service by trade name, trademark, manufacturer, or otherwise does not necessarily constitute or imply its endorsement, recommendation, or favoring by the United States Government or any agency thereof. The views and opinions of authors expressed herein do not necessarily state or reflect those of the United States Government or any agency thereof. 


\section{DISCLAIMER}

Portions of this document may be illegible in electronic image products. Images are produced from the best available original document. 
Printed in the United States of America. Available from

National Technical Information Service

U.S. Department of Commerce

5285 Port Royal Road, Springfield, Virginia 22151

Price: Printed Copy $\$ 3.00$; Microfiche $\$ 0.95$

This report was prepared as an account of work sponsored by the United States Government. Neither the United States nor the United States Atomic Energy Commission, nor any of their employees, nor any of their contractors, subcontractors, or their employees, makes any warranty, express or implied, or assumes any legal liability or responsibility for the accuracy, completeness or usefulness of any information, apparatus, product or process disclosed, or represents that its use would not infringe privately owned rights.

Reference to a company or product name does not imply approval or recommendation of the product by Union Carbide Corporation or the U S Atomic Energy Commission to the exclusion of others that may meet specifications. 


\title{
UNION CARBIDE CORPORATION Nuclear Division
}

\author{
OAK RIDGE Y-12 PLANT
}

Operated under Contract W-7405-eng-26

With the US Atomic Energy Commission

\section{CORRECTION OF INSPECTION DATA FOR PART MISALIGNMENT UTILIZING A SMALL COMPUTER}

T. W. Bookhart

R. J. Easterday

W. Q. Walter

This report was prepared as an account of work sponsored by the United States Government. Neither the United States nor the United States Atomic Energy Commission, nor any of their employees, nor any of their contractors, subcuulracturs, or their employees, makes any warranty, express or implied, or assumes any legal liability or responsibility for the accuracy, completeness or usefulness of any information, anparatus, product or process disclosed, or represents that its use would not infringe privately owned rights.

Oak Ridge, Tennessee 
Document $Y-1755$

TID -4500

DISTRIBUTION:

Atomic Energy Commission-ALO

Adams, G. $M$.

Atomic Energy Commission-0RO

Keller, C. A.

Zachry, D. S., Jr

Battelle-Richland

Dean, R. Y.

Bendix-Kansas City

Sestric, M. D.

Dow-Rocky F lats

Schultz, J. A.

Lawrence Radiation Laboratory

Spies, R. J.

Los Alamos Scientific Laboratory

Parkinson, J. L.

Mason and Hanger-Amarillo

Carpenter, S. D.

Mason and Hanger-Burlington

Jones, K. J.

\section{Monsanto-Mound Laboratories}

Shawhan, C. T.

Oak Ridge Gaseous Diffusion Plant

Easterday, R. J.

Jordan, R. G.

Wilcox, W. J., Jr

$\underline{\text { Oak Ridge } Y-12 \text { Plant }}$

Anderson, P. J. Bell, B. B.

Bernander, N. K.

Blackerby, J.

Bookhart, T. W. (10)

Briscoe, 0.W.

Burkhart,-L. E.

Butler, T. R.

Davenport, C. M.

Davidson, D. R.

Denny, A. (2)

Douglass, T. E.

Ellingson, R. D.

Evans, G. W.

Foulk, D. L.

Green, R. C.

Groppe, W. A.

Haeusler, K. R.

Hemphill, L. F.

Hensley, W. R.

Jackson, V.C.

Jasny, G. R.

Kahl, K. G. 
Keith, Alvin

Kite, H. T.

Lucke, R. P.

Mallard, J. A.

McConnell, O.K.

McLendon, J. D.

Miskell, R. V.

Mitchel, G. W.

O'Hara, M. E.

Oliphant, F, W.

Phillips, L. R.

Perry, A. E.

Robinson, T. W.

Kose, R. F.

Smith, R. D.

Stephens, A. E.

Stoner, H. H.

Trotter, T. C.

Walter, W. Q. (10)

Weathersby, W. E.

Wesley, R. L.

Whitten, L. G.

Yaggi, W. J.

$Y-12$ Central Files (5)

$Y-12$ Central Files (master copy)

$Y-12$ Central Files (route)

$Y-12$ Central Files ( $Y-12 R C)$

\section{Paducah Gaseous Diffusion Plant}

Winkel, R. A.

Sandia-Albuquerque

Emerson, E. L.

\section{Sandia-Livermore}

Madsen, V. P.

Turnbull, C. H.

University Computing Company

Fowler, A. H.

In addition, this report is distributed in accordance with the category UC-32, Mathematics and Computers, as given in the "USAEC Standard Distribution Lists for Unclassified Scientific and Technical Reports", TID-4500. 
Algorithms have been developed for determining and correcting for the misalignment of the axes of a surface of revolution with respect to the axes of a dimensional inspection machine. Measured deviations from part datum surfaces are used to compute the part misalignment. These algorithms have been programmed and incorporated as a portion of the control program for a twoaxis, computer-controlled dimensional inspection machine. 


\section{CONTENTS}

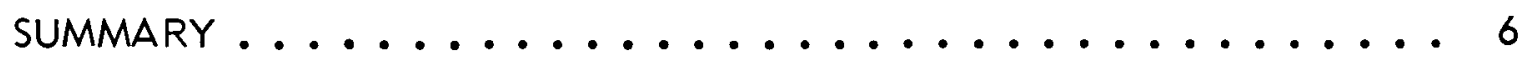

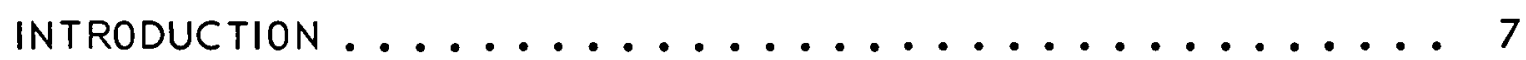

CORRECTING INSPECTION DATA BY USING A SMALL COMPUTER . . . 9

Mathematical Merivatinn of Errors Due to Part Misalianment . . . . . 9

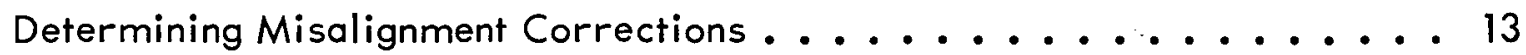

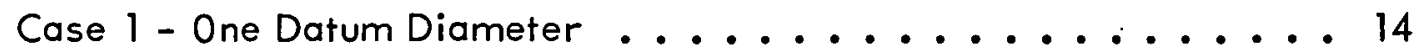

Case 2 - Datum Surface and Datum Diameter ......... 17

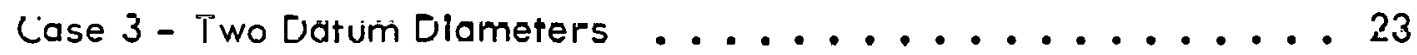

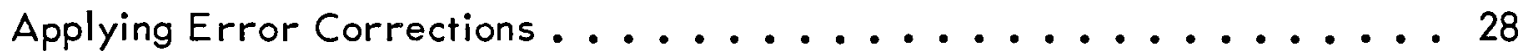

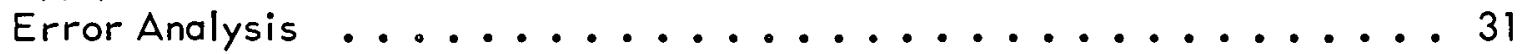

Assumption that $\cos \alpha_{x}=\cos \alpha_{y}=1 \ldots \ldots . \ldots . \ldots . . . \ldots 31$

Assumption that the Surface is Locally a Plane ......... 32

Effect of Out of Roundness on the Calculated Off Center . . . . . 34

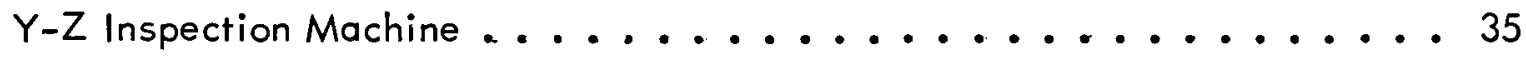

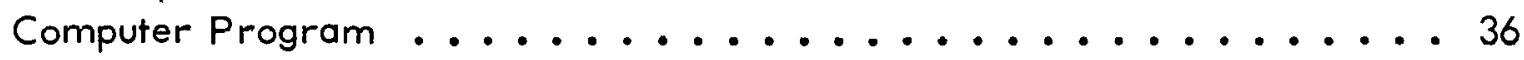

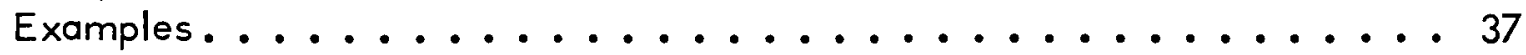

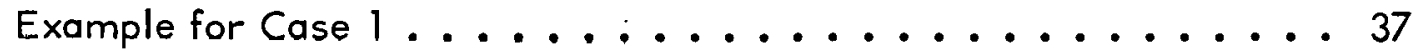

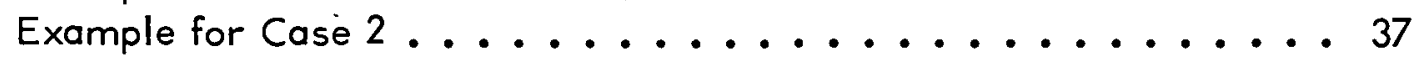

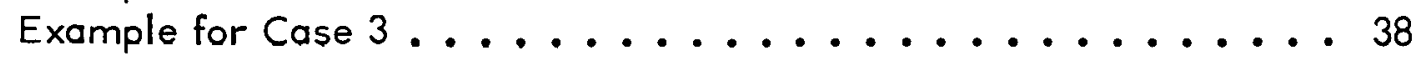




\section{SUMMARY}

Algorithms have been developed at the Oak Ridge $Y-12$ Plant ${ }^{(a)}$ for determining and correcting for the misalignment of the axes of a surface of revolution with respect to the axes of a dimensional inspection machine. The misalignment is determined from measured deviations taken at the datum surfaces of the part. Correction for this misalignment is then applied on line to all subsequent measurements: Three types of parts (cases) are considered:

1. A part in which deviations are taken from one datum diameter and used in determining misalignment. Part off center (translation perpendicular to the axis of the part) only is computed and used in applying corrections.

2. A part in which deviations from a datum surface and a datum diameter are used in calculating the misalignment. Part off center, tilt, and vertical shift (translation along the axis of the part) are computed and corrected for.

3. A part in which deviations from two datum diameters are used for the misalignment calculation. Part off center and tilt are computed and corrected for in this case.

These algorithms were developed for use with a Bendix ${ }^{(b)} Y-Z$ dimensional inspection machine. This machine, a two-axis, computer-controlled measuring machine, utilizes a PDP-8T computer $(c)$ for its control. The algorithms have been programmed for the PDP-8I and incorporated as a portion of the machine control program.

(a) Operated for the US Atomic Energy Commission by Union Carbide Corporation's Nuclear Division.

(b) Bendix Corporation, Automation \& Measurement Division, Dayton, Ohio.

(c) Digital Equipment Corporation, Maynard, Massachusetts. 


\section{INTRODUCTION}

When a part is inspected by a numerically controlled inspection machine, it is assumed that the coordinate frame of the part and the gage are coincident. However, they are not generally coincident, and the difference in reference frames causes the measured error to include not only manufacturing error but error in alignment as well.

With the advent of small computers being used for controlling dimensional inspection machines, the possibility of an on-line correction for part misalignment becomes attractive. With little or no additional hardware cost, the computer which controls the machine can also be used to make these corrections. It then becomes a matter of developing suitable software for determining the desired corrections and applying them to the measured data.

The purpose then of this effort is to develop algorithms which are suitable for use by small computers. Simplifying assumptions will be made when possible to reduce the highly nonlinear character of this problem. Only parts which are surfaces of revolution will be considered. 
THIS PAGE ,

\section{WAS INTENTIONALLY \\ LEFT BLANK}




\section{MATHEMATICAL DERIVATION OF ERRORS DUE TO PART MISALIGNMENT}

The inspection process that is considered here is concerned with inspecting parts which are surfaces of revolution. The inspection consists of taking a set of deviation measurements around the part at various distances along the axis of symmetry. If the coordinate frame of the part and gage are not coincident, the measured deviations include error in alignment as well as manufacturing error. Figure 1 illustrates this condition.

Let $\left(r,, z_{1}, \theta_{1}\right)$ be the cylindrical coordinates of a point on a surface of revolution and let $\gamma$ be the normal angle at the point. Assume that, locally, the part is a plane containing the point $\left(r_{1}, z_{1}, \theta_{1}\right)$ with the normal, $\gamma$. Then the equation of the surface (locally) is:

$$
\cos \gamma \cos \theta_{1}\left(x-x_{1}\right)+\cos \gamma \sin \theta_{1}\left(y-y_{1}\right)+\sin \gamma\left(z-z_{1}\right)=0
$$

where:

$$
\begin{gathered}
x_{1}=r_{1} \cos \theta_{1} ; \\
y_{1}=r_{1} \sin \theta_{1}, \text { and } \\
z_{1}=z_{1} .
\end{gathered}
$$

If the surface was found to be at $\left(x_{2}, y 2, z_{2}\right)$, then the error that would be measured (normal error) is the normal distance from the point $\left(x^{\prime} 2, y_{2}, z_{2}\right)$ to the plane defining the part locally (see Figure 2). That is:

$$
e=|\bar{n} \cdot \bar{u}|
$$

where:

e represents the normal error measured,

$\bar{n}$ the unit normal vector of the surface, and

$\bar{u}$ a vector from the point $\left(x_{2}, y_{2}, z_{2}\right)$ to a known point of the surface, $\left(x_{1}, y_{1}, z_{1}\right)$. 


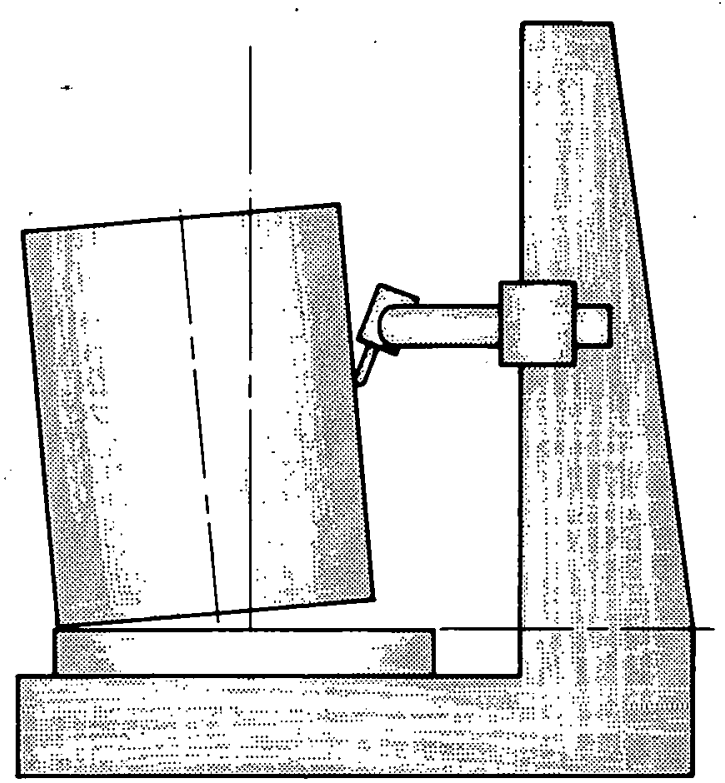

Figure 1. PART MISALIGNED ON AN INSPECTION MACHINE.

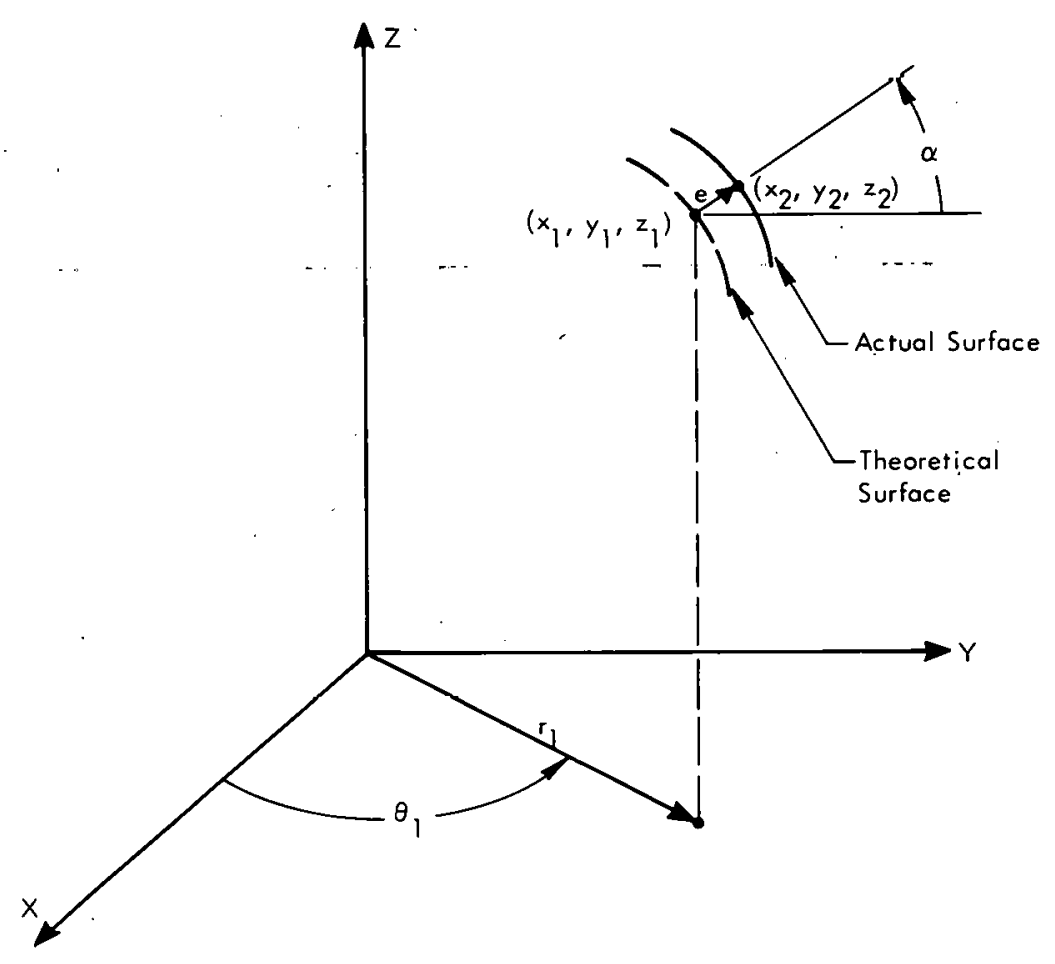

Figure 2. ERROR BETWEEN AN ACTUAL SURFACE AND A THEORETICAL SURFACE. 
Then:

$$
e=\cos \gamma \cos \theta_{1}\left(x_{2}-x_{1}\right)+\cos \gamma \sin \theta_{1}\left(y_{2}-y_{1}\right)+\sin \gamma\left(z_{2}-z_{1}\right) .
$$

Now, let the part be rotated and translated by a previously computed transformation so that the point $\left(x_{2}, y_{2}, z_{2}\right)$ becomes $\left(x_{2}^{\prime \prime \prime}, y_{2}^{\prime \prime \prime}, z_{2}^{\prime \prime \prime}\right)$. Then, the error after making the transformation, e', will be (see Figure 3):

$$
e^{\prime}=\cos \gamma \cos \theta_{1}\left(x_{2}{ }^{\prime \prime \prime}-x_{1}\right)+\cos \gamma \sin \theta_{1}\left(y_{2}{ }^{\prime \prime \prime}-y_{1}\right)+\sin \gamma\left(z_{2}{ }^{\prime \prime}-z_{1}\right) \text {. }
$$

Then, combining Equations 3 and 4 gives:

$e^{\prime}-c=\cos \gamma^{\prime} \cos \theta_{1}\left(x_{2}{ }^{\prime \prime \prime}-x_{2}\right)+\cos \gamma \sin \theta_{1}\left(y_{2}{ }^{\prime \prime \prime}-y_{.2}\right)+\sin \gamma\left(z_{2}{ }^{\prime \prime \prime}-z_{2}\right)$, or

$e^{\prime}=e+\cos \gamma \cos \theta_{1}\left(x_{2}{ }^{\prime \prime \prime}-x_{2}\right)+\cos \gamma \sin \theta_{1}\left(y_{2}{ }^{\prime \prime \prime}-y_{2}\right)+\sin \gamma\left(z_{2}^{\prime \prime \prime}-z_{2}\right)$.

Thus, Equation 6 gives an expression for the deviation that would be measured if the part were repositioned.

Now consider a coordinate frame which has been rotated about the $Y$ axis by an angle of $\alpha_{y}$, rotated about the $X$ axis by an angle $\alpha_{x}$, and translated by $\left(x_{0}, y_{0}, z_{0}\right)$. These transformations are illustrated by suitable drawings.

For rotation about the $Y$ axis (Figure 4):

$$
\begin{gathered}
x^{\prime}=x \cos \alpha_{y}-z \sin \alpha_{y^{\prime}} \\
y^{\prime}=y, \text { and } \\
z^{\prime}=x \sin \alpha_{y}+z \cos \alpha_{y} .
\end{gathered}
$$

For rotation about the $X$ axis (Figure 5):

$$
\begin{gathered}
x^{\prime \prime}=x^{\prime}, \\
y^{\prime \prime}=y^{\prime} \cos \alpha_{x}+z^{\prime} \sin \alpha_{x} \text {, and } \\
z^{\prime \prime}=-y^{\prime} \sin \alpha_{x}+z^{\prime} \cos \alpha_{x} \text {, or }
\end{gathered}
$$




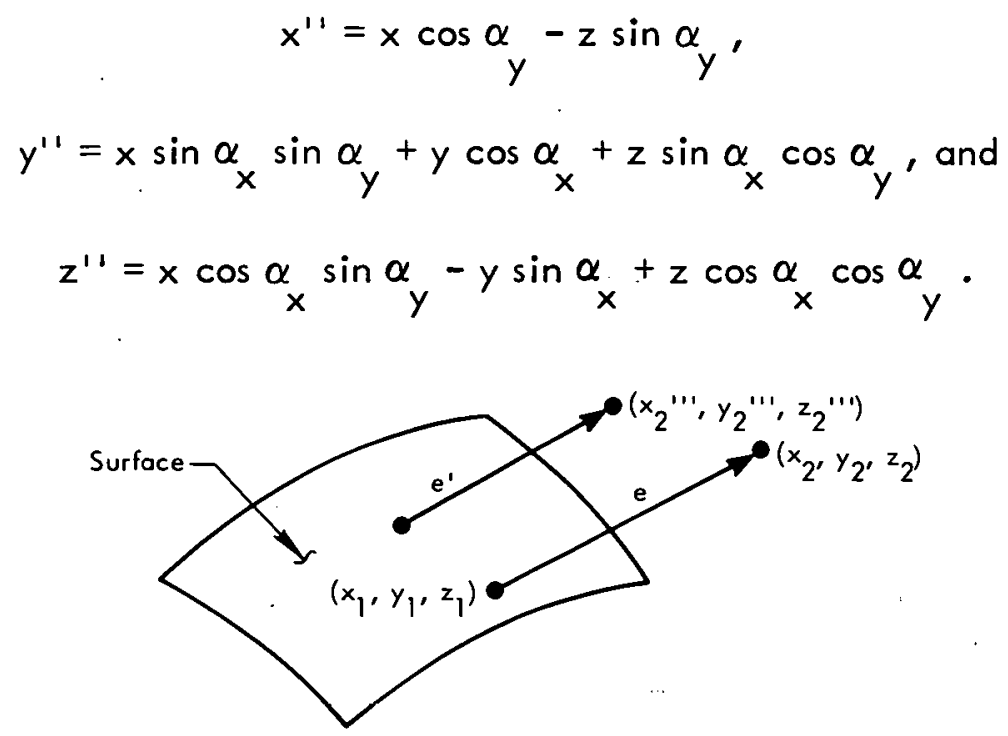

Figure 3. ERROR BEFORE AND AFTER TRANSFORMATION.

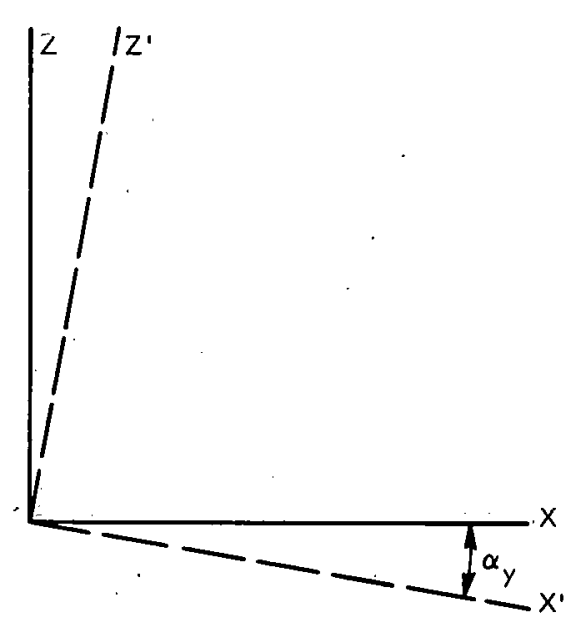

Figure 4. ROTATION ABOUT THE Y AXIS.

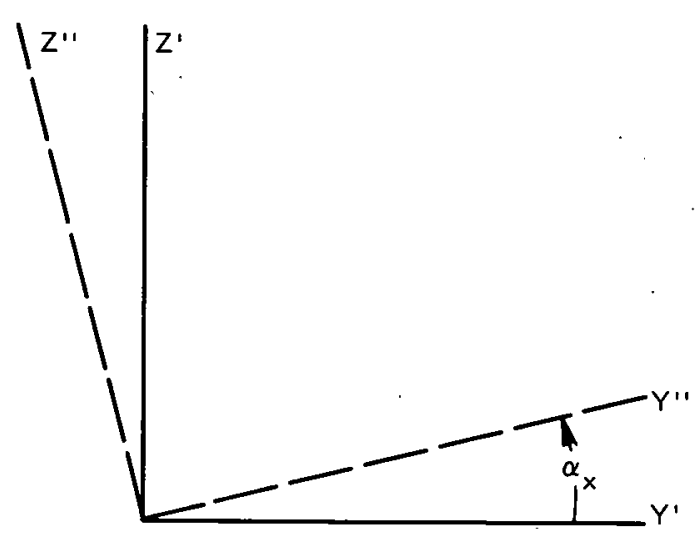

Figure 5. ROTATION ABOUT THE X AXIS. 
For the translation (Figure 6):

$$
\begin{gathered}
x^{\prime \prime \prime}=x^{\prime \prime}-x_{0}, \\
y^{\prime \prime \prime}=y^{\prime \prime}-y_{0} \text {, and } \\
z^{\prime \prime \prime}=z^{\prime \prime}-z_{0} \text {, or } \\
x^{\prime \prime \prime}=x \cos \alpha_{y}-z \sin \alpha_{y}-x_{0}, \\
y^{\prime \prime \prime}=x \sin \alpha_{x} \sin \alpha_{y}+y \cos \alpha_{x}+z \sin \alpha_{x} \cos \alpha_{y}-y_{0} \text {, and } \\
z^{\prime \prime \prime}=x \cos \alpha_{x} \sin \alpha_{y}-y \sin \alpha_{x}+z \cos \alpha_{x} \cos \alpha_{y}-z_{0} .
\end{gathered}
$$

Now, assume that these rotations are small so that:

$$
\cos \alpha_{y}=\cos \alpha_{x}=1 \text {, }
$$

then:

$$
\begin{gathered}
x^{\prime \prime \prime}-x=-z \sin \alpha_{y}-x_{0}, \\
y^{\prime \prime \prime}-y=x \sin \alpha_{x} \sin \alpha_{y}+z \sin \alpha_{x}-y_{0}, \text { and } \\
z^{\prime \prime \prime}-z=x \sin \alpha_{y}-y \sin \alpha_{x}-z_{0} .
\end{gathered}
$$

Combining Equations 22 - 24 into Equation 6 gives:

$$
\begin{gathered}
e^{\prime}=e+\cos \gamma \cos \theta_{1}\left(-z_{2} \sin \alpha_{y}-x_{0}\right)+\cos \gamma \sin \theta_{1}\left(x_{2} \sin \alpha_{x} \sin \alpha_{y}+\right. \\
\left.z_{2} \sin \alpha_{x}-y_{0}\right)+\sin y\left(x_{2} \sin \alpha_{y}-y_{2} \sin \alpha_{x}-z_{0}\right) .
\end{gathered}
$$

Thus, Equation 25 can be an expression for the corrected error, e', as a function of the measured error, e, and the rotations and translation.

\section{DE TERMINING MISALIGNMENT CORRECTIONS}

The part misalignment will be determined from a series of measured deviations taken at the datum surfaces of the part. Three types of parts (cases) will be considered: 


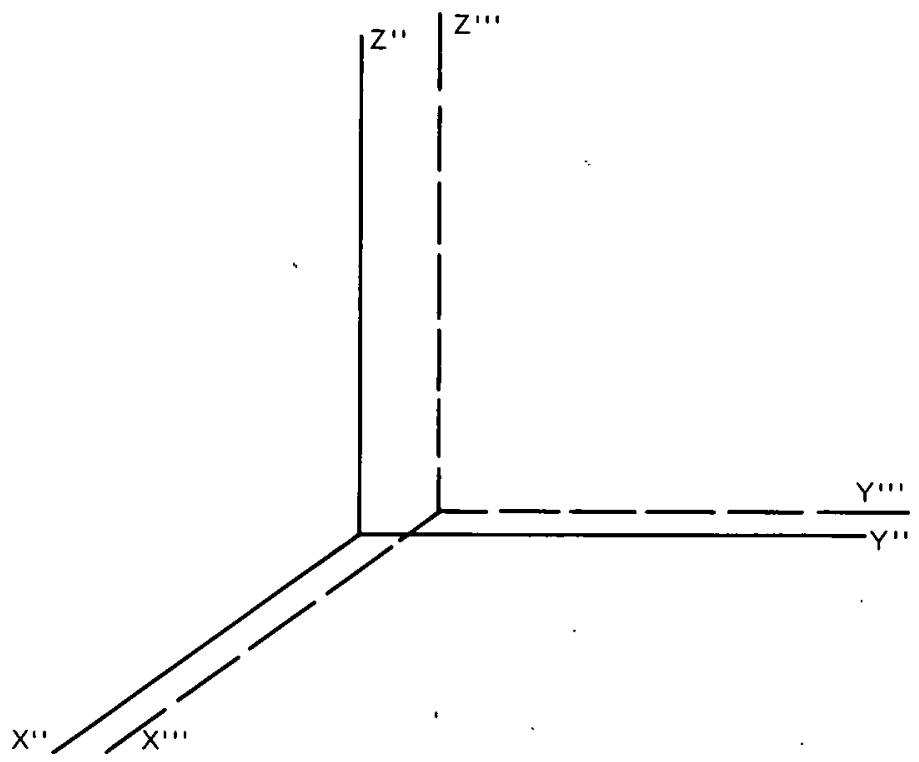

Figure 6. TRANSLATION OF AXES.

Case 1. A part in which deviations are taken from one datum diameter to determine part misalignment. Part off center. ( $x_{0}, Y_{0}$ translation) only will be computed.

Case 2. A part in which deviations from a datum surface and a datum diamcter are used in ealiulating lite inisuliymmenl. Purt off center ( $x_{0}, y_{0}$ translation), tilt (angles $\alpha_{x}$ and $\alpha_{y}$ ), and vertical shift ( $z_{0}$ translation) will be computed.

Case 3. A part in which deviations from two datum diameters are used in calculating the misalignment. Part off center ( $x_{0}, y_{0}$ translation) and tilt (angles $\alpha_{x}$ and $\alpha_{y}$ ) will be determined.

\section{Case 1 - One Datum Diameter}

In this case, the $x y$ plane of the part will be assumed to be coincident with the xy plane of the inspection machine. (That is, the datum surface of the part is coincident with the rotary table of the machine.) (Therefore, for this case, the tilt $\left(\alpha_{x}\right.$ and $\left.\alpha_{y}\right)$ and vertical shift $\left(z_{0}\right)$ are assumed to be zero. Figure 7 illustrates this condition.

A series of measurements, $e_{i}$, will be taken at the datum diameter and used in determining the off-center translation $\left(x_{0}, y_{0}\right)$. Assuming that:

$$
\sin \alpha_{x}=\sin \alpha_{y}=z_{0} \equiv 0
$$




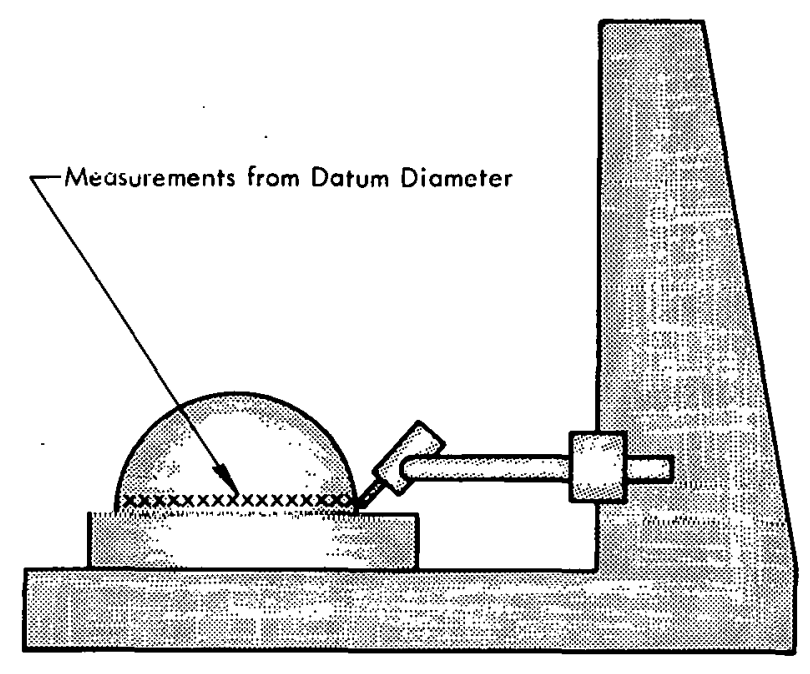

Figute 7. OHAE-DATUM-DIMMETEŔ GANE.

Equation 25 reduces to:

$$
e^{\prime}{ }_{i}=e_{i}-x_{o} \cos \gamma \cos \theta_{i}-y_{o} \cos \gamma \sin \theta_{i}
$$

To determine $x_{0}$ and $y_{0}$, the values chosen will be those that minimize the corrected error, $e^{\prime} i^{\prime}$ in the least square sense. That is, find $x_{0}$ and $y_{0}$ so that:

$$
\sum_{i=1}^{N}\left(e^{\prime}\right)^{2} \text { is a minimum. }
$$

Let:

$$
S=\sum_{i=1}^{N}\left(e_{i}^{\prime}\right)^{2} .
$$

Then, solving $\partial s / \partial x_{0}=0$ and $\partial s / \partial y_{0}=0$ for $x_{0}$ and $y_{0}$ will give the values of $x_{0}$ and $y_{0}$ which minimize the corrected errors in the least square sense.

This action reduces to solving:

$$
\begin{gathered}
\left(\sum_{i=1}^{N} \cos ^{2} \theta_{i} \cos ^{2} \gamma\right) x_{0}+\left(\sum_{i=1}^{N} \sin \theta_{i} \cos \theta_{i} \cos ^{2} \gamma\right) y_{0}= \\
\sum_{i=1}^{N} e_{i} \cos \theta_{i} \cos \gamma, \text { and }
\end{gathered}
$$




$$
\begin{gathered}
\left(\sum_{i=1}^{N} \sin \theta_{i} \cos \theta_{i} \cos ^{2} \gamma\right) x_{0}+\left(\sum_{i=1}^{N} \sin ^{2} \theta_{1} \cos ^{2} \gamma\right) y_{0}= \\
\underset{i=1}{N} e_{i} \sin \theta_{i} \cos \gamma \cdot
\end{gathered}
$$

If the $N$ measurements are taken at values of $\theta_{i}$, which are equally spaced around the part, then:

$$
\sum_{i=1}^{N} \cos ^{2} \theta_{i} \simeq \frac{N}{2 \pi} \int_{0}^{2 \pi} \cos ^{2} \theta d \theta=N / 2
$$

Similarly:

$$
\begin{aligned}
& \sum_{i=1}^{N} \sin ^{2} \theta_{i} \simeq N / 2, \text { and } \\
& N \\
& \sum \sin 0_{i} \cos \theta_{i} \simeq 0 .
\end{aligned}
$$

Utilizing these relations, Equations 28 and 29 reduce to:

$$
\begin{gathered}
(N / 2) x_{0}=(1 / \cos \gamma) \sum_{i=1}^{N} e_{i} \cos \theta_{i}, \text { and } \\
(N / 2) y_{0}=(1 / \cos \gamma) \sum_{i=1}^{N} e_{i} \sin \theta_{i} .
\end{gathered}
$$

Then:

$$
\begin{gathered}
x_{0}=(2 / N)(1 / \cos \gamma) \sum_{i=1}^{N} e_{i} \cos \theta_{i} \text {, and } \\
y_{0}=(2 / N)(1 / \cos \gamma) \sum_{i=1}^{N} e_{i} \sin \theta_{i} .
\end{gathered}
$$


Thus, Equations 35 and 36 are expressions for the part off-center components as a function of the normal deviations measured at the datum diameter.

\section{Case 2 - Datum Surface and Datum Diameter}

In this case the part could be tilted and shifted vertically as well as off center. Figure 8 illustrates this type of part inspection. A series of measurements would be taken on the datum surface and the datum diameter to determine the misalignment. The procedure for computing the misalignment is as follows:

1. Take a series of deviation measurements on the datum surface.

2. From the measurements obtained on the datum surface, fit a least square plane. The normal vector of the plane will be chosen as the axis of the part. From this axis, the part tilt can be computed.

3. Also utilizing the measured deviations from the datum plane, determine the translation along the axis of the part, $z_{0}$.

4. Take a series of deviation measurements at the datum diameter.

5. Correct these measured deviations for tilt and $z_{0}$ translation.

6. Determine the part off center, $x_{0}$ and $y_{0}$, using the corrected deviations at the diameter.

Determination of the Least Square Plane - The equation of a plane is:

$$
\begin{aligned}
& a x+b y+c z+d=0, \text { or } \\
& a^{\prime} x+b^{\prime} y+c^{\prime} z+1=0 .
\end{aligned}
$$

Given deviations $e_{i}$ at the points, in cylindrical coordinates $\left(R, Z, \theta_{i}\right)$ of the datum plane, then the points where the surface was found (assuming here that the surface normal angle, $\gamma$, is $90^{\circ}$ ) are:

$$
\begin{gathered}
\mathbf{x}_{\mathbf{i}}=R \cos \theta_{\mathbf{i}}, \\
y_{\mathbf{i}}=R \sin \theta_{\mathbf{i}}, \text { and } \\
\mathbf{z}_{\mathbf{i}}=\mathbf{z}+\mathbf{e}_{\mathbf{i}},
\end{gathered}
$$




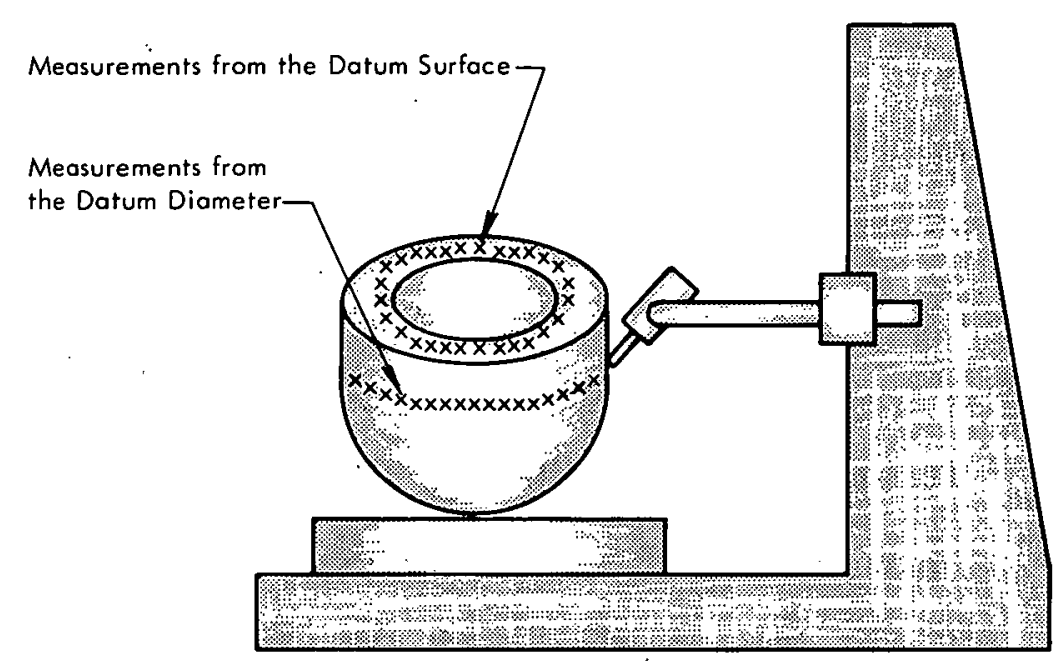

Figure 8. DATUM-SURFACE AND DATUM-DIAMETER CASE.

where:

ei represents the deviations normal to the surface.

The distance, $d$, from the point to the plane is:

$$
d=\frac{\left|a^{\prime} x_{i}+b^{\prime} y_{i}+c^{\prime} z_{i}+1\right|}{a^{\prime 2}+b^{\prime 2}+c^{\prime 2}}
$$

Now, the constants $a^{\prime}, b^{\prime}, c^{\prime}$ are determined so that this distance is a minimum in the least square sense. - [Since only the vector $\left(a^{\prime}, b^{\prime}, c^{\prime}\right)$ is of interest, the denominator can be disregarded and the vector normalized later.]

Let:

$$
\begin{gathered}
S=\sum_{i=1}^{N}\left(a^{\prime} x_{i}+b^{\prime} y_{i}+c^{\prime} z_{i}+1\right)^{2}, \text { or } \\
S=\sum_{i=1}^{N}\left[a^{\prime} R \cos \theta_{i}+b^{\prime} R \sin \theta_{i}+c^{\prime}\left(z+e_{i}\right)+1\right]^{2} .
\end{gathered}
$$

For a minimum, it is necessary that:

$$
\frac{\partial S}{\partial a^{\prime}}=\frac{\partial S}{\partial b^{\prime}}=\frac{\partial S}{\partial c^{\prime}}=0 .
$$


These equations become:

$$
\begin{aligned}
& a^{\prime} R^{2}\left(\sum_{i=1}^{N} \cos ^{2} \theta_{i}\right)+b^{\prime} R^{2}\left(\sum_{i=1}^{N} \sin \theta_{i} \cos \theta_{i}\right)+c^{\prime} R \sum_{i=1}^{N}\left(Z+e_{i}\right) \cos \theta_{i}+ \\
& \sum_{i=1}^{N} \cos \theta_{i}=0, \\
& a^{\prime} R^{2}\left(\Sigma \sin \theta_{i} \cos \theta_{i}\right)+b^{\prime} R^{2}\left(\sum_{i=1}^{N} \sin ^{2} \theta_{i}\right)+c^{\prime} R \sum_{i=1}^{N}\left(Z+e_{i}\right) \sin \theta_{i}+ \\
& \sum_{i=1}^{N} \sin \theta_{i}=0, \text { and } \\
& a^{\prime} R \sum_{i=1}^{N}\left(Z+e_{i}\right) \cos \theta_{i}+b^{\prime} R \sum_{i=1}^{N}\left(Z+e_{i}\right) \sin \theta_{i}+ \\
& c^{\prime} \sum_{i=1}^{N}\left(Z+e_{i}\right)^{2}+\sum_{i=1}^{N}\left(Z+e_{i}\right)=0
\end{aligned}
$$

Assuming again that the measurements are taken at values of $\theta_{\mathbf{i}}$ which are equally spaced around the part, then:

$$
\begin{gathered}
\sum_{i=1}^{N} \sin \theta_{i}=\sum_{i=1}^{N} \cos \theta_{i}=\sum_{i=1}^{N} \sin \theta_{i} \cos \theta_{i}=0 \text {, and } \\
\sum_{i=1}^{N} \cos ^{2} \theta_{i}=\sum_{i=1}^{N} \sin ^{2} \theta_{i}=N / 2 .
\end{gathered}
$$

These equations become:

$$
\left(R^{2} N / 2\right) a^{\prime}+\left[R \sum_{i=1}^{N}\left(Z+e_{i}\right) \cos \theta_{i}\right] c^{\prime}=0
$$




$$
\begin{gathered}
\left(R^{2} N / 2\right) b^{\prime}+\left[R \sum_{i=1}^{N}\left(Z+e_{i}\right) \sin \theta_{i}\right] c^{\prime}=0, \text { and } \\
R \sum_{i=1}^{N}\left(Z+e_{i}\right) \cos \theta_{i}\left[a^{\prime}+R \sum_{i=1}^{N}\left(Z+e_{i}\right) \sin \theta_{i}\right] b^{\prime}+ \\
\\
{\left[\begin{array}{c}
N \\
i=1
\end{array}\left(Z+e_{i}\right)^{2}\right] c^{\prime}=-\underset{i=1}{N}\left(Z+e_{i}\right) .}
\end{gathered}
$$

Solving Equations $48-50$ for $a^{\prime}, b^{\prime}$, and $c^{\prime}$ results in:

$$
\begin{gathered}
a^{\prime}=-K \sum_{i=1}^{N} e_{i} \cos \theta_{i}, \\
b^{\prime}=-K \sum_{i=1}^{N} e_{i} \sin \theta_{i} \text {, and } \\
c^{\prime}=K(R N / 2),
\end{gathered}
$$

where:

$$
K=\frac{-\left(N Z+\sum_{i=1}^{N} e_{i}\right)}{R\left\{N / 2\left[N Z^{2}+2 Z \sum_{i=1}^{N} e_{i}+\sum_{i=1}^{N} e_{i}^{2}\right]-\left[\sum_{i=1}^{N} e_{i} \sin \theta_{i}\right]^{2}-\left[\sum_{i=1}^{N} e_{i} \cos \theta_{i}\right]^{2}\right\}}
$$

Since interest is only in the normalized vector $(a, b, c)$, Equations $51-53$ can be simplified to:

$$
\begin{gathered}
a^{\prime \prime}=-\sum_{i=1}^{N} e_{i} \cos \theta_{i} ; \\
b^{\prime \prime}=-\sum_{i=1}^{N} e_{i} \sin \theta_{i} \text {, and } \\
c^{\prime \prime}=R N / 2 .
\end{gathered}
$$


The unit normal vector $(a, b, c)$ of the plane then becomes:

$$
\begin{gathered}
a=a^{\prime \prime} / D, \\
b=b^{\prime \prime} / D \text {, and } \\
c=c^{\prime \prime} / D,
\end{gathered}
$$

where:

$$
D=\sqrt{a^{\prime \prime 2}+b^{\prime \prime 2}+c^{\prime \prime 2}} \text {. }
$$

Vector $(a, b, c)$ represents the axis of the part, and from it the part tilt can be determined.

Determination of the Part Tilt - To determine the rotation, $\alpha_{x}$ and $\alpha_{y}$, from this part axis, rotate the vector $(a, b, c)$ so that it becomes coincident with the axis of the machine:

$$
R\left(\begin{array}{l}
a \\
b \\
c
\end{array}\right)=\left(\begin{array}{l}
0 \\
0 \\
1
\end{array}\right)
$$

where:

$$
R=\left(\begin{array}{ccc}
\cos \alpha_{y} & 0 & -\sin \alpha_{y} \\
\sin \alpha_{x} \sin \alpha_{y} & \cos \alpha_{x} & \sin \alpha_{x} \cos \alpha_{y} \\
\cos \alpha_{x} \sin \alpha_{y} & -\sin \alpha_{x} & \cos \alpha_{x} \cos \alpha_{y}
\end{array}\right) .
$$

Then:

$$
\begin{gathered}
a \cos \alpha_{y}-c \sin \alpha_{y}=0, \\
a \sin \alpha_{x} \sin \alpha_{y}+b \cos \alpha_{x}+c \sin \alpha_{x} \cos \alpha_{y}=0 \text {, and } \\
a \cos \alpha_{x} \sin \alpha_{y}-b \sin \alpha_{x}+c \cos \alpha_{x} \cos \alpha_{y}=1 .
\end{gathered}
$$

Again, assuming that the rotations are small and that

$$
\cos \alpha_{x}=\cos \alpha_{y}=1
$$


Equations $60-62$ reduce to:

$$
\begin{gathered}
a-c \sin \alpha_{y}=0, \\
a \sin \alpha_{x} \sin \alpha_{y}+b+c \sin \alpha_{x}=0, \text { and } \\
a \sin \alpha_{y}-b \sin \alpha_{x}+c=1, \text { or } \\
\sin \alpha_{y}=a / c .
\end{gathered}
$$

Also:

$$
\begin{aligned}
\sin \alpha_{x} & =-b /\left(a \sin \alpha_{y}+c\right) \\
& =-b /\left(a^{2} / c+c\right) .
\end{aligned}
$$

If $a \ll 1$, then $a^{2} / c \ll 1$ and a good approximation is:

$$
\sin \alpha_{x}=-b / c \text {. }
$$

Equations 66 and 68 give expressions for $\sin \alpha_{x}$ and $\sin \alpha_{y}$ in terms of the $a, b$, and $c$. which are given by Equations $57-59$.

Determination of the $Z$ Translation - The measured deviations from the datum plane can now be corrected for tilt, as found previously, and a new deviation, $e^{\prime} i$, found.

The value of $z_{0}$ that is desired is that which will minimize the remaining deviations of the datum plane in the least square sense. That is, find $z_{0}$ so that:

$$
S=\sum_{i=1}^{N}\left(\bar{e}_{i}\right)^{2} \text { is a minimum, }
$$

where:

$$
\bar{e}_{i}=e^{\prime}{ }_{i}-z_{0} \text { (from Equation 25). }
$$

By solving $\partial S / \partial z_{0}=0$, an expression for $z_{0}$ is obtained, thus:

$$
z_{0}=V / N \sum_{i=1}^{N} e_{i}^{\prime} .
$$


If the measurements are taken at values of $\theta_{i}$ which are equally spaced around the part,

$$
\begin{aligned}
& \stackrel{\sum}{i=1}_{i}^{N} e^{\prime}=\sum_{i=1}^{N} e_{i}, \text { and } \\
& z_{0}=1 / N \underset{i=1}{N} e_{i},
\end{aligned}
$$

where:

$\theta_{i}$ reprecente the meacured normal deviatione of the datum plane.

Thus, Equation 70 gives an expression for the $z_{0}$ translation as a function of the deviation measured at the datum plane.

Determination of the Off Center - Let $e_{i}$ be the normal deviations at the measured datum diameter and let $e^{\prime} i$ be those deviations corrected for tilt and $z_{0}$ translation as found from the datum plane. (Equation 25 gives the expression for the corrected error.) Then the part off center is obtained from Equations 34 and 36. That is,

$$
\begin{gathered}
x_{0}=(2 / N)(1 / \cos \gamma) \sum_{i=1}^{N} e_{i}^{\prime} \cos \theta_{i} \text {, and } \\
y_{0}=(2 / N)(1 / \cos \gamma) \sum_{i=1}^{N} e^{\prime} \sin \theta_{i},
\end{gathered}
$$

where:

$e^{\prime} i$ represents the corrected normal deviations from the datum diameter, and

$\gamma$ the normal angle at the diameter.

Case 3 - Two Datum Diameters - In this case, a series of measurements will be taken at each of the datum diameters. The part tilt and off center will be determined using these data. Vertical shift, $z_{0}$ translation, will be assumed to he zero in this case. Figure 9 shows this type of part inspection. 


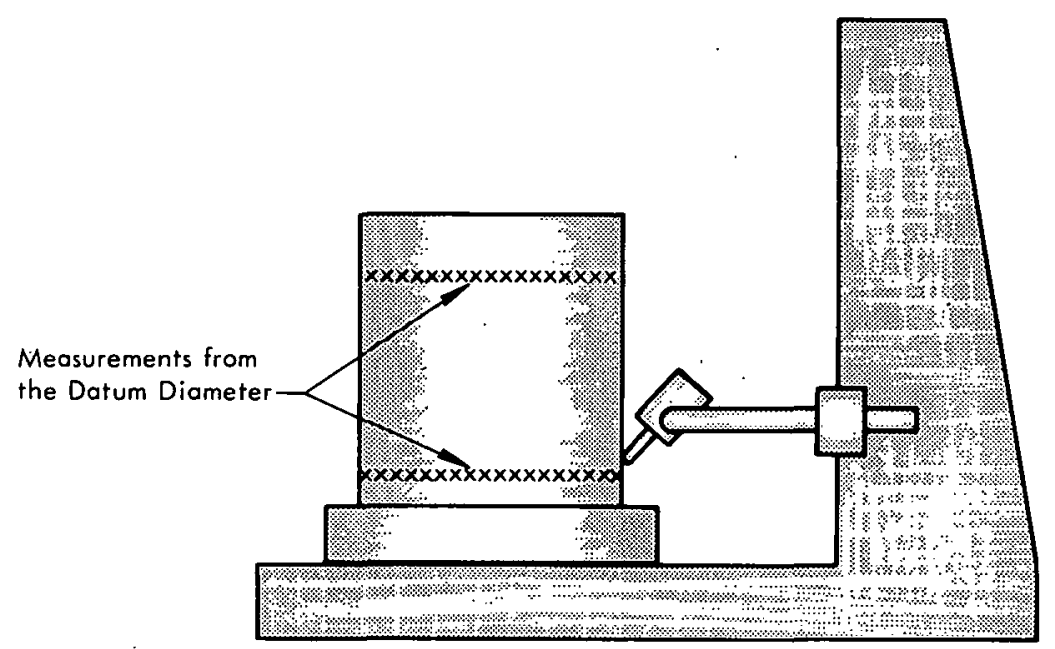

Figure 9. TWO-DATUM-DIAMETER CASE.

This case proved to be more difficult than was expected, principally because when a surface of revolution is tilted, the cross section seen by the measuring machine is elliptical rather than circular. For the case where the surface is cylindrical, the center of the ellipse lies along the axis of the cylinder and the eccentricity of the ellipse is small for small tilts. However, if the surface is noncylindrical, the center of the ellipse does not lie along the axis (see Figures 10 and 11). Therefore, Equations 35 and 36 cannot be directly used to determine the part center at the measured diameter.

If Equations 35 and 36 are used after correction has been made for tilt, the computed center will then lie along the axis of the part. Let $\left(x_{1}, y_{1}\right)$ be the center of the first measured diameter after removal of tilt and $\left(x_{2}, y_{2}\right)$ the center at the second diameter after tilt has been removed. Then:

$$
\begin{aligned}
& x_{1}=(2 / N)\left(1 / \cos \gamma_{1}\right) \sum_{i=1}^{N} e_{1}{ }_{i} \cos \theta_{i}{ }^{\prime} \\
& y_{1}=(2 / N)\left(1 / \cos \gamma_{1}\right) \sum_{i=1}^{N} e_{1}{ }_{i} \sin \theta_{i}, \\
& x_{2}=(2 / N)\left(1 / \cos \gamma_{2}\right) \sum_{i=1}^{N} e^{\prime}{ }^{\prime} \cos \theta_{i}, \text { and } \\
& y_{2}=(2 / N)\left(1 / \cos \gamma_{2}\right) \sum_{i=1}^{N} e_{2^{\prime}} \sin \theta_{i}
\end{aligned}
$$




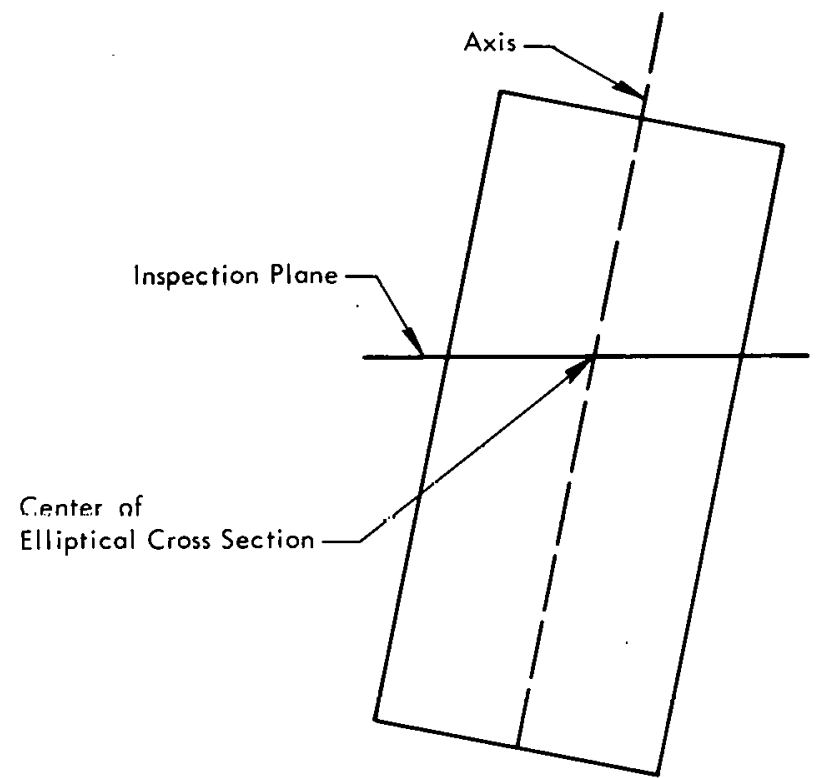

Figure 10. TILTED CYLINDER.

where:

${ }^{e}{ }_{i}$ represents the deviations at the first diameter corrected fortilt, and $e^{e^{\prime}}{ }_{i}$ the deviations at the second diameter corrected for tilt.

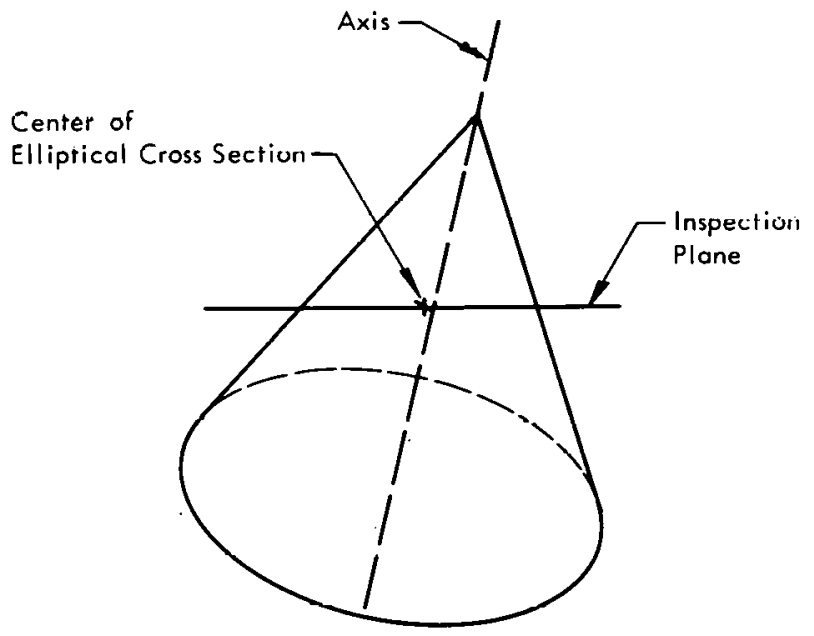

Figure 11. TIILTED CONE. 
Substituting Equation 25 into Equations $71-74$ and simplifying yields:

$$
\begin{gathered}
x_{1}=(2 / N)\left(1 / \cos \gamma_{1}\right)\left[\sum_{i=1}^{N} e_{1} \cos \theta_{i}+(N / 2) \sin \alpha_{y}\left(r_{1} \sin \gamma_{1}-z_{1} \cos \gamma_{1}\right)\right], \\
y_{1}=(2 / N)\left(1 / \cos \gamma_{1}\right)\left[\begin{array}{l}
N \\
\sum \\
i=1
\end{array} e_{1} \sin \theta_{i}+(N / 2) \sin \alpha_{x}\left(-r_{1} \sin \gamma_{1}+z_{1} \cos \gamma_{1}\right)\right], \\
x_{2}=(2 / N)\left(1 / \cos \gamma_{2}\right)\left[\begin{array}{c}
N \\
\sum \\
i=1
\end{array} e_{2} \cos \theta_{i}+\right. \\
\left.(N / 2) \sin \alpha_{y}\left(r_{2} \sin \gamma_{2}-z_{2} \cos \gamma_{2}\right)\right], \text { and } \\
y_{2}=(2 / N)\left(1 / \cos \gamma_{2}\right)\left[\begin{array}{c}
N \\
\sum \\
i=1
\end{array} e_{i} \sin \theta_{i}+\right. \\
\left.(N / 2) \sin \alpha_{x}\left(-r_{2} \sin \gamma_{2}+z_{2} \cos \gamma_{2}\right)\right]
\end{gathered}
$$

where:

${ }^{e} \mathbf{l}_{\mathbf{i}}$ represents the measured normal deviations at the first-diameter;

${ }^{e} 2_{i}$ the measured normal deviations at the second diameter,

$\gamma_{1}$ the normal angle at the first diameter,

$\gamma_{2}$ the normal angle at the second diameter,

$\left(r_{2}, z_{1}\right)$ the cylindrical coordinates of the inspected point at the first diameter, and

$\left(r_{2}, z_{2}\right)$ the cylindrical coordinates of the inspection point at the second diameter.

Since $\left(x_{1}, y_{1}\right)$ and $\left(x_{2}, y_{2}\right)$ lie along the axis of the part after tilt has been removed:

$$
\begin{gathered}
x_{1}=x_{2}=x_{0} \text {, and } \\
y_{1}=y_{2}=y_{0} .
\end{gathered}
$$


Setting $x_{1}=x_{2}$ and $y_{1}=y_{2}$, and solving for $\sin \alpha_{y_{1}} \sin \alpha_{x}$ results in:

$\begin{aligned} \sin \alpha_{y}= & \frac{(2 / N)\left(1 / \cos \gamma_{2}\right) \sum_{i=1}^{N} e_{2} \cos \theta_{i}-(2 / N)\left(1 / \cos \gamma_{1}\right) \sum_{i=1}^{N} e_{i} \cos \theta_{i}}{\left(1 / \cos \gamma_{1}\right)\left(r_{1} \sin \gamma_{1}-z_{1} \cos \gamma_{1}\right)-\left(1 / \cos \gamma_{2}\right)\left(r_{2} \sin \gamma_{2}-z_{2} \cos \gamma_{2}\right)} \text {, and } \\ \sin \alpha_{x}= & -\frac{(2 / N)\left(1 / \cos \gamma_{2}\right) \sum_{i=1}^{N} e_{2} \sin \theta_{1}-(2 / N)\left(1 / \cos \gamma_{1}\right) \sum_{i=1}^{N} e_{1} \sin \theta_{i}}{\left(1 / \cos \gamma_{1}\right)\left(r_{1} \sin \gamma_{1}-z_{1} \cos \gamma_{1}\right)-\left(1 / \cos \gamma_{2}\right)\left(r_{2} \sin \gamma_{2}-z_{2} \cos \gamma_{2}\right)}\end{aligned}$

Thus, these tilt components (Equations 79 and 80) can be directly obtained from the measured deviations at the two datum diameters. If the surface is cylindrical at the two diameters, $\cos \gamma_{1}=\cos \gamma_{2}=1$ and $\sin \gamma_{1}=\sin \gamma_{2}=0$, then:

$$
\begin{gathered}
\sin \alpha_{y}=\frac{(2 / N) \sum_{i=1}^{N} e_{{ }_{i}} \cos \theta_{i}-(2 / N){ }_{i=1}^{N} e_{l_{i}} \cos \theta_{i}}{\left(z_{2}-z_{1}\right)} \text {, and } \\
\sin \alpha_{x}=-\frac{(2 / N) \sum_{i=1}^{N} e_{2} \sin \theta_{i}-(2 / N) \sum_{i=1}^{N} e_{1} \sin \theta_{i}}{\left(z_{2}-z_{1}\right)} .
\end{gathered}
$$

The axis vector $(a, b, c)$ of the part can be derived from Equations 79 and 80 . That is:

$$
\begin{gathered}
c=1 / \sqrt{\sin ^{2} \alpha_{x}+\sin ^{2} \alpha_{y}+1}, \\
b--c \sin \alpha_{x}, \text { urid } \\
a=c \sin \alpha_{y} .
\end{gathered}
$$

The translation can be directly obtained from: 


$$
\begin{aligned}
& x_{0}=x_{1} \\
& =(2 / N)\left(1 / \cos \gamma_{1}\right)\left[\sum_{i=1}^{N} e_{1_{i}} \cos \theta_{i}+\right. \\
& \left.(N / 2) \sin \alpha_{y}\left(r_{1} \sin \gamma_{1}-z_{1} \cos \gamma_{1}\right)\right] \text {, and } \\
& y_{0}=y_{1} \\
& =(2 / N)\left(1 / \cos \gamma_{1}\right)\left[\begin{array}{l}
N \\
\sum=1
\end{array} e_{i} \sin \theta_{i}+\right. \\
& \left.(N / 2) \sin \alpha_{x}\left(-r_{1} \sin \gamma_{1}+z_{1} \cos \gamma\right)\right] \text {. }
\end{aligned}
$$

Thus, Equations 79 and 80 . fully determine the tilt components for this case and Equations 86 and 87 the off-center components.

\section{APPLYING ERROR CORRECTIONS}

Let the input coordinate data to the correction routine be ball-center data (this would be the information passed along on a punched tape for positioning the inspection machine) in cylindrical coordinates.

Then (see Figure 12):

$$
\begin{gathered}
r_{1}=r_{1}-r_{b} \cos \gamma, \\
z_{1}=z_{1}-r_{b} \sin \gamma, \text { and } \\
\theta_{1}=\theta_{1},
\end{gathered}
$$




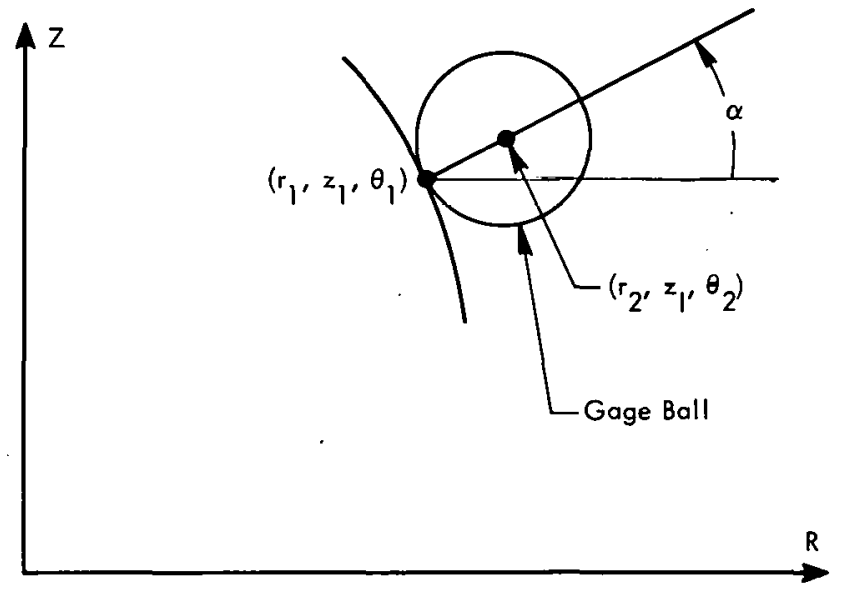

Figure 12. CYLINDRICAL COORDINATES.

where:

$$
\begin{aligned}
& \left(r_{1}, z_{1}, \theta_{1}\right) \text { are the cylindrical coordinates of the ball center, } \\
& \gamma \quad \text { is the normal angle, and } \\
& r_{b} \quad \text { is the radii of the gage ball. }
\end{aligned}
$$

The values used by Equation 25 for computing the corrected deviations are the coordinates of the part surface where it was found by the inspection. That is (see Figure 13):

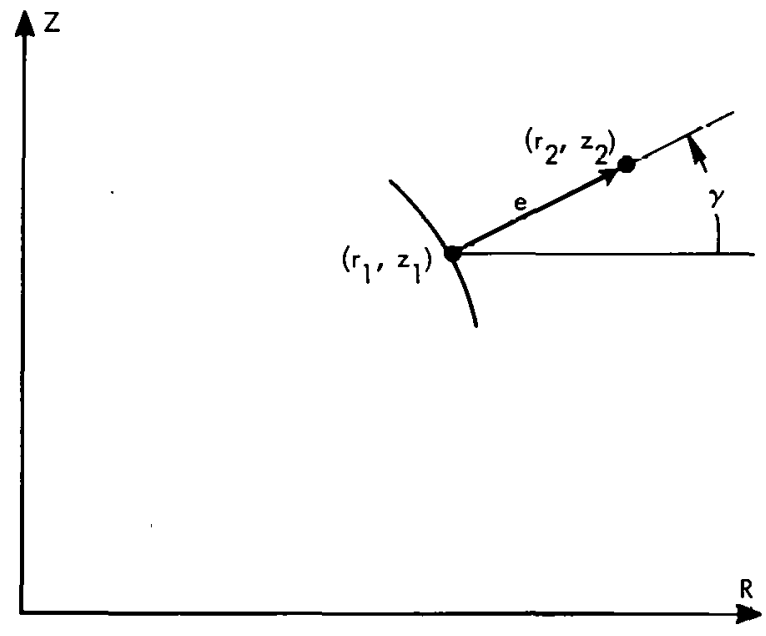

Figure 13. COORDINATES OF THE PART SURFACE. 


$$
\begin{aligned}
& r_{2}=r_{1}+e \cos \gamma, \text { and } \\
& z_{2}=z_{1}+e \sin \gamma \text {. Or } \\
& r_{2}=r_{1}-\left(r_{b}-e\right) \cos \gamma, \text { and } \\
& z_{2}=z_{1}-\left(r_{b}-e\right) \sin \gamma .
\end{aligned}
$$

Then the corrected error (Equation 25) can be expressed in terms of the coordinate input data that would appear in the machine punched tape, $\left(r_{l}, z_{1}\right)$.

$$
\begin{aligned}
& e^{\prime}=e-\left[z_{1}-\left(r_{b}-e\right) \sin \gamma\right] \cos \gamma \cos \theta \sin \alpha_{y} \\
& +\left[r_{1}-\left(r_{b}-e\right) \cos \gamma\right] \cos \gamma \cos \theta \sin \theta \sin \alpha_{x} \sin \alpha_{y} \\
& +\left[z_{1}-\left(r_{b}-e\right) \sin \gamma\right] \cos \gamma \sin \theta \sin \alpha_{x} \\
& +\left[r_{1}-\left(r_{b}-e\right) \cos \gamma\right] \cos \theta \sin \gamma \sin \alpha_{y} \\
& -\left[r_{1}-\left(r_{b}-e\right) \cos \gamma\right] \sin \theta \sin \gamma \sin \alpha_{x} \\
& -x_{0} \cos \gamma \cos \theta-y_{0} \cos \gamma \sin \theta-z_{0} \sin \gamma \text {. } \\
& e^{\prime}=e-\left(z_{1}-r_{b} \sin \gamma\right) \cos \gamma \cos \theta \sin \alpha_{y} \\
& +\left(r_{1}-r_{b} \cos \gamma\right) \cos \gamma \cos \theta \sin \theta \sin \alpha_{x} \sin \alpha_{y} \\
& +\left(z_{1}-r_{b} \sin \gamma\right) \cos \gamma \sin \theta \sin \alpha_{x} \\
& +\left(r_{1}-r_{b} \cos \gamma\right) \cos \theta \sin \gamma \sin \alpha_{y} \\
& -\left(r_{1}-r_{b} \cos \gamma\right) \sin \theta \sin \gamma \sin \alpha_{x} \\
& -x_{0} \cos \gamma \cos \theta-y_{0} \cos \gamma \sin \theta-z_{0} \sin \gamma \\
& +e \cos ^{2} \gamma \cos \theta \sin \theta \sin \alpha_{x} \sin \alpha_{y} \text {. }
\end{aligned}
$$

The final term in Equation 96 has a second-order effect on the corrected error and therefore can be neglected.

On many inspection machines, the origin of the $Z$ axis may "float", and the $Z$ coordinates appearing in the punched tape could be translated from the datum 
surface. A simple translation of $Z$ in Equation 96 will result in rotations being computed and applied about an origin at the datum surface.

The inspection process described herein is concerned with inspecting parts which are surfaces of revolution. The inspection consists of taking a series of deviation measurements around the part at various distances along the axis of symmetry (latitudes). Therefore, the cylindrical coordinates, $(r|, z|)$, and the normal angle, $\gamma$, will be constant for a series of measurements. Thus, the amount of computation required for individual corrected errors can be reducod by rowriting Equation 9h ns:

$$
\begin{aligned}
e^{\prime}= & +\left[-\bar{z} \cos \gamma \sin \alpha_{y}+\bar{r} \sin \gamma \sin \alpha_{y}-x_{0} \cos \gamma\right] \cos \theta \\
& +\left[\bar{z} \cos \gamma \sin \alpha_{x}-\bar{r} \sin \gamma \sin \alpha_{x}-y_{0} \cos \gamma\right] \sin \theta \\
& +\left[\bar{r} \cos \gamma \sin \alpha_{x} \sin \alpha_{y}\right] \sin \theta \cos \theta \\
& -z_{0} \sin \gamma,
\end{aligned}
$$

where:

$$
\begin{gathered}
\bar{z}=z_{1}-r_{b} \sin \gamma-z_{d}, \text { and } \\
\bar{r}=r_{1}-r_{b} \cos \gamma .
\end{gathered}
$$

$z_{d}$ represents the $Z$ coordinate of the datum surface,

$z_{1}$ the $Z$ coordinate of the gage ball center,

$r_{1}$ the R coordinate of the gage ball center, and

$\gamma$ the normal angle.

\section{ERROR ANALYSIS}

Several simplifying assumptions were made in developing the algorithm. The effects of these assumptions will now be examined.

Assumption that $\operatorname{Cos} \alpha_{x}=\operatorname{Cos} \alpha_{y}=1$

If the rotations are less than five minutes of arc (this small tilt will produce a measured deviation of 14.5 mils at the top of a ten-inch cylinder), then: 


$$
|1-\cos \alpha|<1 \times 10^{-6}
$$

This assumption will therefore produce no appreciable error in the calculations. Assumption that the Surface is Locally a Plane

This assumption, that the surface is locally a plane, will produce the greatest source of error in the computation. A detailed analysis follows for the case where the surface inspected is spherical:

Let the surface to be inspected be a sphere and let $\left(x_{1}, y_{1}, z_{1}\right)$ be the programmed inspection point (see Figure 14).

If the point actually measured is $(x, y, z)$, then the error, $\epsilon$, in the computation resulting from the surface curvature will be:

$$
\begin{gathered}
\epsilon-\cos \gamma \cos \theta\left(x-x_{l}\right)+\cos \gamma \sin \theta\left(y-y_{1}\right)+\sin \gamma\left(z-z_{l}\right), \text { or } \\
\epsilon=\cos \gamma \cos \theta\left(x-R_{c} \cos \gamma \cos \theta\right)+\cos \gamma \sin \theta\left(y-R_{c} \cos \gamma \sin \theta\right) \\
\quad+\sin \gamma\left(z-R_{c} \sin \gamma\right), \text { or } \\
\epsilon=x \cos \gamma \cos \theta+y \cos \gamma \sin \theta+z \sin \gamma-R_{c} .
\end{gathered}
$$

Let the point $(x, y, z)$ be located a distance: $d=\sqrt{d_{1}^{2}+d_{2}^{2}+d_{3}^{2}}$ from $\left(x_{1}, y_{1} ; z_{1}\right)$ so that:

$$
\begin{gathered}
x=x_{1}+d_{1}, \\
y=y_{1}+d_{2}, \text { and } \\
z=z_{1}+d_{3} .
\end{gathered}
$$

Then:

$$
\begin{gathered}
\epsilon=\left(R_{c} \cos \theta \cos \gamma+d_{1}\right) \cos \gamma \cos \theta+\left(R_{c} \cos \gamma \sin \theta+d_{2}\right) \cos \gamma \sin \theta \\
+\left(R_{c} \sin \gamma+d_{3}\right) \sin \gamma-R_{c}, \text { or } \\
\epsilon=d_{1} \cos \gamma \cos \theta+d_{2} \cos \gamma \sin \theta+d_{3} \sin \gamma .
\end{gathered}
$$




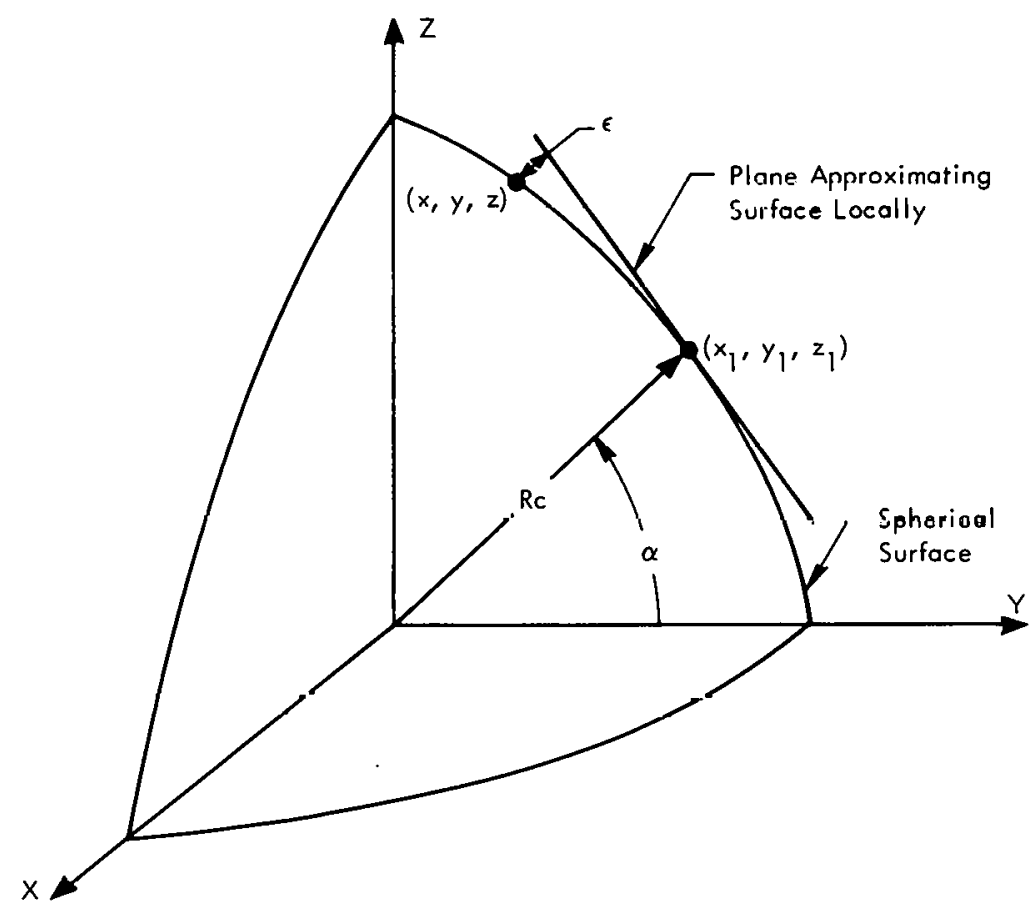

Figure 14. PROGRAMMED INSPECTION POINT.

But the point $(x, y, z)$ lies on the sphere so that:

$$
\begin{gathered}
\left(x_{1}+d_{1}\right)^{2}+\left(y_{1}+d_{2}\right)^{2}+\left(z_{1}+d_{3}\right)^{2}=R_{c}, \\
\left(R_{c} \cos \theta \cos \gamma+d_{1}\right)^{2}+\left(R_{c} \cos \gamma \sin \theta+d_{2}\right)^{2}+\left(R_{c} \sin \gamma+d_{3}\right)=R_{c}, \text { or } \\
2 R_{c}\left(\cos \gamma \cos \theta d_{1}+\cos \gamma \sin \theta d_{2}+\sin \gamma d_{3}\right)=-\left(d_{1}^{2}+d_{2}^{2}+d_{3}^{2}\right) .
\end{gathered}
$$

Solving Equation 108 for $\left(\cos \gamma \cos \theta d_{1}+\cos \gamma \sin \theta d_{2}+\sin \gamma d_{3}\right)$ and substituting into Equation 105 produces:

$$
\epsilon=\frac{d_{1}^{2}+d_{2}^{2}+d_{3}^{2}}{2 R_{c}} .
$$

Thus, the error caused by assuming that the surface locally is a plane is:

$$
\epsilon=d^{2} / 2 R_{c} \text {, }
$$


where:

d represents the distance between the programmed inspection point and the point measured (the amount of misalignment), and

$R_{c}$ the radius of curvature of the surface.

This error is depicted in Figure 15.

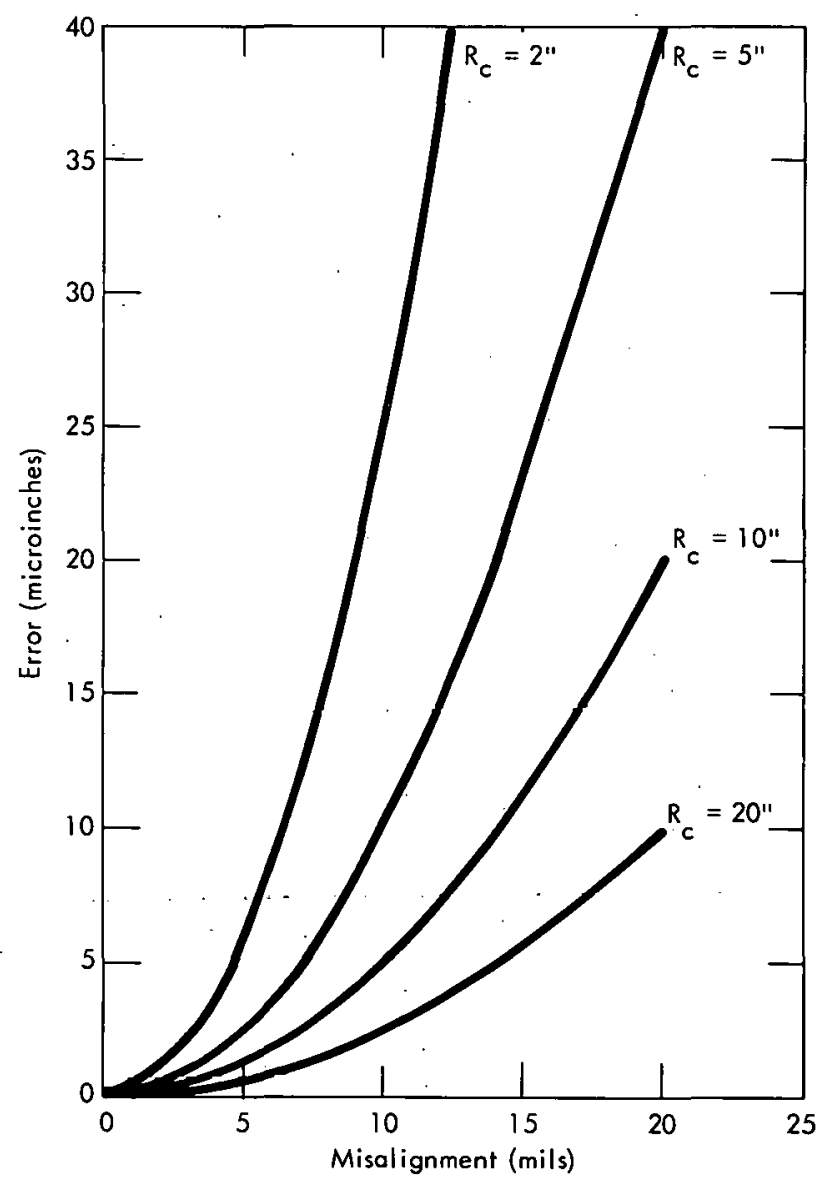

Figure 15. EFFECT OF SURFACE CURVATURE ON THE MISALIGNMENT CORRECTION. (Where $R_{c}$ is the Radius of Curvature)

\section{Effect of Out of Roundness on the Calculated Off Center}

"Out of roundness" is a term applied to parts whose cross sections assume a shape other than circular when in the free state. This noncircular cross section will result in an error in the computed part center. The amount of error increases as the out of roundness and/or the amount of off center increases. 
Past experience has shown that most out-of-round parts assume a near elliptical cross section. Therefore, Equations 35 and 36 , for computing the part center, were used (with $N=256$ ) to compute the center of a part $\left(x_{0}, y_{0}\right)$ when the part was off center and the cross section elliptical. Figure 16 relates the error caused by out of roundness. These data were computed for an elliptical cross section with a semiminor axis equal to 10 inches. The quantity, out of roundness, is one half the difference between the lengths of the semiaxes.

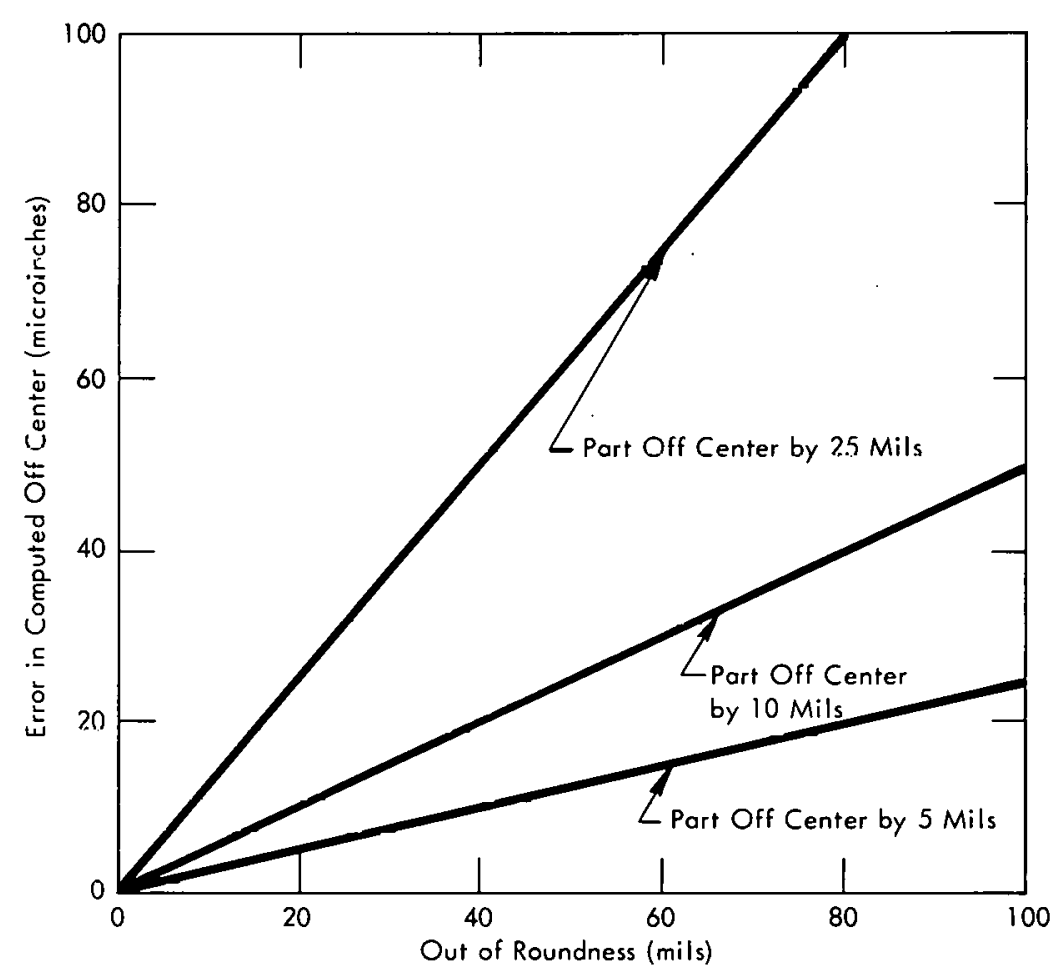

Figure 16. EFFECT OF OUT OF ROUNDNESS ON THE OFF-CENTER CALCULATION FOR A TEN-INCH-RADIUS OFF-CENTERED PART.

\section{Y-Z INSPECTION MACHINE}

The algorithms previously described were developed for use with a Bendix $Y-Z$ dimensional inspection machine. This machine, a two-axis computercontrolled measuring machine, utilizes a PDP-81 computer for its control (see Figure 17). The algorithms have been programmed for the PDP-81 and incorporated as a portion of the machine control program.

The positioning information comprises the input to the control computer by means of a conventional numerical-control $(\mathrm{N} / \mathrm{C})$ punched tape. This punched tape, however, also contains the other data needed for the misalignment correction. For each inspection point, the part normal angle is included. This 


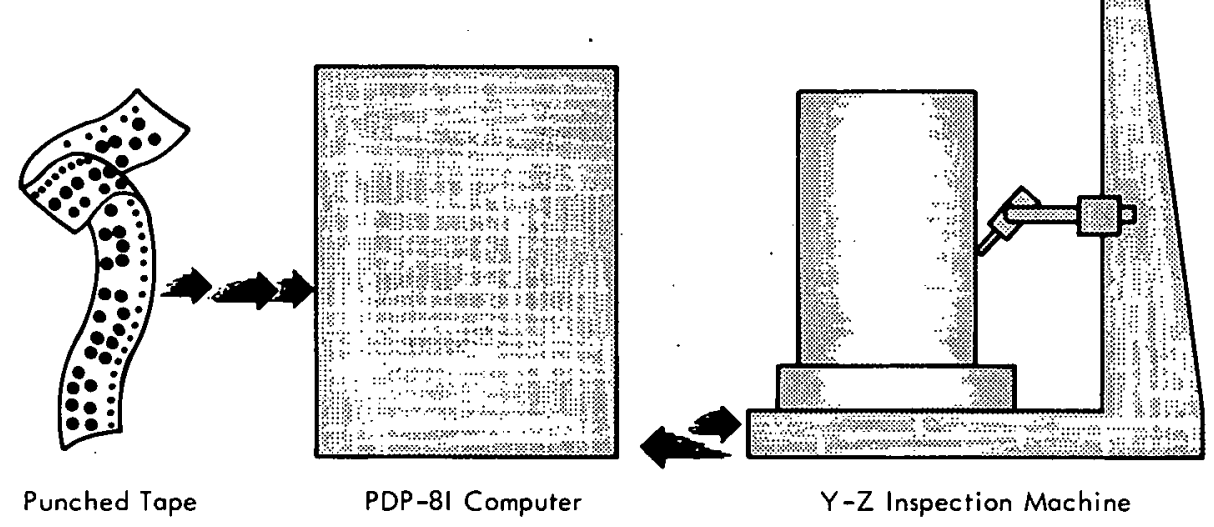

Figure 17. MAJOR COMPONENTS OF THE Y-Z INSPECTION MACHINE.

information appears in the punched tape with the word address, $d$. The radius of the gage ball appears as a " $t$ " code in the N/C tape.

The type of part being inspected, Case 1, 2, or 3(Page 14), is indicated by " $m$ " codes. The $m$ code appears in the block which positions the gage at the given datum surface. Figure 18 relates the $m$ codes to the three cases.

\section{COMPUTER PROGRAM}

The computer program developed for the Bendix $Y-Z$ dimensional inspection machine was written so that it can be used on many different types of inspection machines with only minor changes. The program is for a Digital Equipment Corporation P.DP-81 computer with an EAE (KE-81 extendedarithmetic element):

The program requires $3 \mathrm{~K}$ of core including Floating Point Package 4 (Digital $8-25-F)$. Over half of the core requirement is for the floating point package and about $0.5 \mathrm{~K}$ of this package contains extended functions that are not used, which can be taken out if storage becomes a problem.

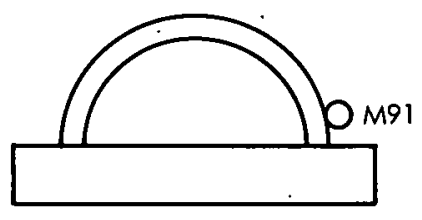

(a) Single Diameter (Case 1)

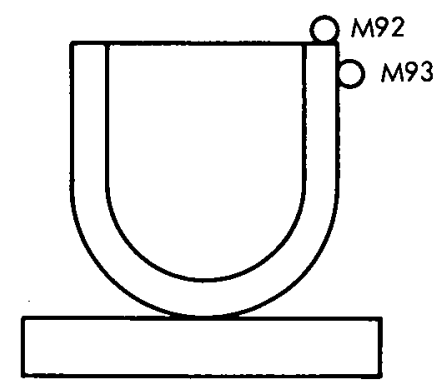

(b) Surface and Diameter (Cose 2)

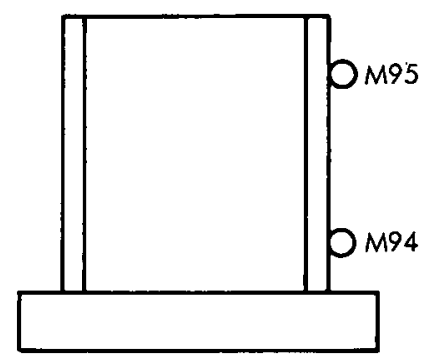

(c) Two Diameter (Case 3)

Figure 18. M CODES USED TO INDICATE THE TYPE OF INSPECTION. 
The correction program is called as a subroutine by the machine monitor program after each error sample is taken as the rotary table turns. The correction program takes the reading, calculates the misalignment correction for that point, and corrects the reading and returns control to the machine monitor. The correction takes 38 milliseconds per reading and the $\mathrm{Y}-\mathrm{Z}$ machine takes 256 readings per sweep for a total calculation time of 9.73 seconds per sweep, or a 32 percent burden for a spindle speed of $2 \mathrm{rpm}$.

The correction program has two major parts. The first part of the program collects data during the calibration sweep(s) and then calculates the misalignment parameters for the part setup. These parameters are output on the hardcopy output for the part and are used in the remaining sweeps to correct the readings for misalignment. The second part of the correction program takes the calculated misalignment parameters and corrects the readings during additional sweeps to give a corrected chart recording and hard-copy output. A flowchart of the program is presented in Figure 19.

\section{EXAMPLES}

In order to test the algorithms developed here, a computer routine was written to simulate a mispositioned part and calculate the deviations the inspection machine would measure. These calculated deviations of a hypothetically mispositioned part were used in testing the PDP-8I program. An example for each type of part inspection follows.

\section{Example for Case 1}

For this example, a 10-inch-radius hemisphere was hypothetically off centered by $7.07 \mathrm{mils}\left(x_{0}=y_{0}=5 \mathrm{mils}\right)$ and deviations computed at 16 equally spaced points around the part. The deviations were calculated for a 5/32-inch-diameter gage ball at a gage angle of 45 degrees. Figure 20 illustrates the part and Table 1 gives a summary of the results. Point 1 was used as the datum diameter.

\section{Example for Case 2}

The part shown in Figure 21 was used for this example. The part was hypothetically translated by $x_{0}=y_{0}=z_{0}=5$ mils and tilted by $\alpha_{x}=\alpha_{y}=1$ minute (a total tilt of 1.414 minutes). Again, the deviations were computed at 16 points equally spaced around the part for a $5 / 32$-inch-diameter gage ball at a gage 


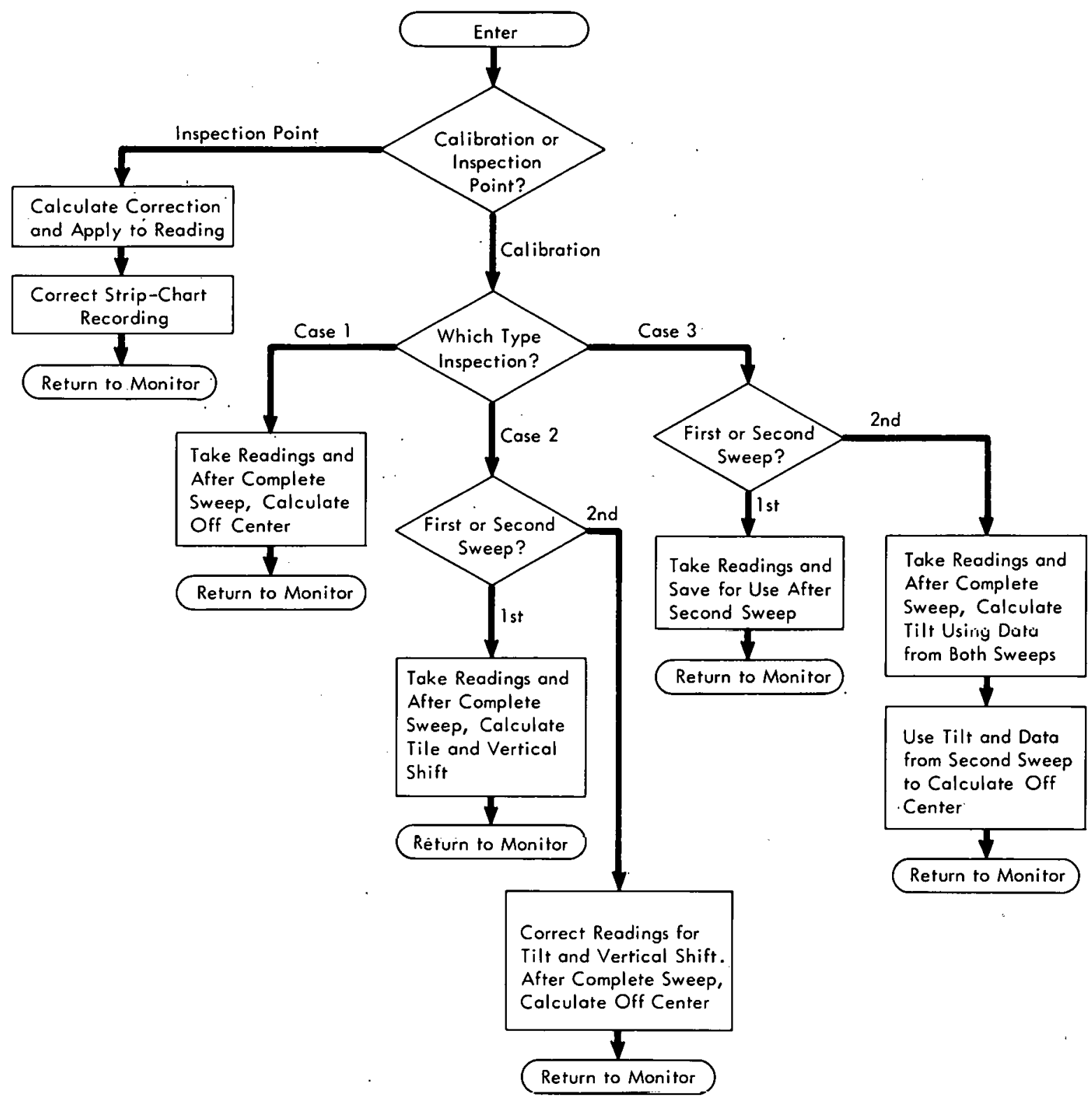

Figure 19. PROGRAM FLOW CHART.

angle of 45 degrees. Table 2 summarizes the results. Point 1 was used as the datum surface and Point 2 the diameter.

\section{Example for Case 3}

Figure 22 illustrates the part used for this example. The part was hypothetically translated by $x_{0}=y_{0}=5$ mils and tilted by $\alpha_{x}=\alpha_{y}=1$ minute (a total tilt of 1.414 minutes). The deviations were calculatedat 16 equally spaced points around the part for a 5/32-inch-diameter gage ball at a gage angle of 45 degrees. 


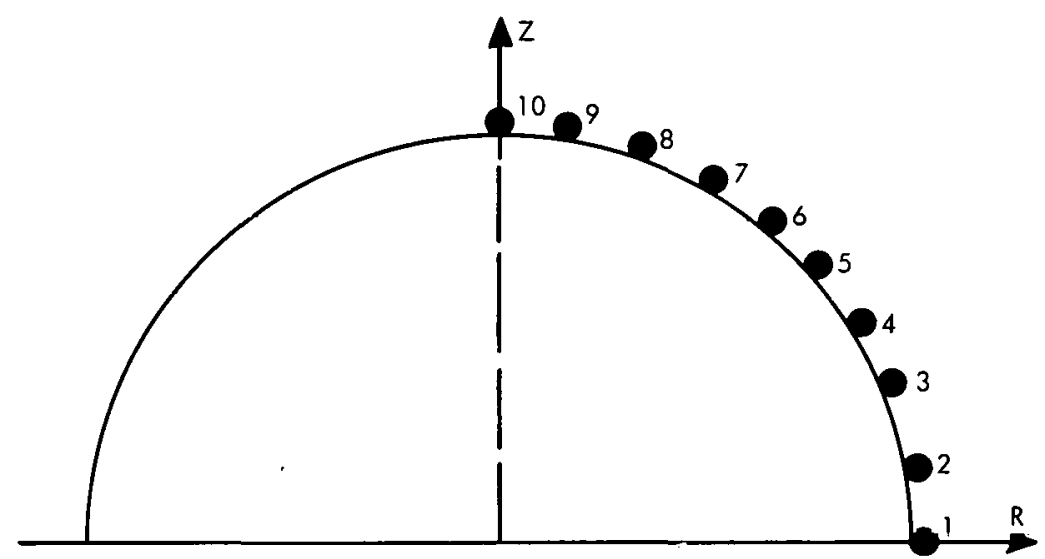

Figure 20. PART USED IN EXAMPLE FOR CASE 1.

Iäblè I

COMPUTED OFF CENTER (CASE 1)

(X Offset (mils), 5.000; Y Offset (mils), 5.001)

\begin{tabular}{|c|c|c|c|c|c|c|c|c|}
\hline \multirow{2}{*}{$\begin{array}{l}\text { Point } \\
\text { Number }\end{array}$} & \multirow{2}{*}{$\begin{array}{c}\text { Coordinates of } \\
\text { Ball Center } \\
\left(r_{1}, z_{1}\right)\end{array}$} & \multirow{2}{*}{$\begin{array}{c}\text { Normal } \\
\text { Angle } \\
\text { (degrees) }\end{array}$} & \multicolumn{2}{|c|}{$\begin{array}{c}\text { Measured Error } \\
(\mathrm{mi} / \mathrm{s})\end{array}$} & \multicolumn{2}{|c|}{$\begin{array}{c}\text { Normal Error } \\
\text { (mils) }\end{array}$} & \multicolumn{2}{|c|}{$\begin{array}{c}\text { Corrected Error } \\
(\text { mils })\end{array}$} \\
\hline & & & Maximum & Minimum & Maximum & Minimum & Maximum & Minimum \\
\hline 1 & $(10.0781,0)$ & 0 & 9.997 & -10.003 & 7.069 & -7.073 & -0.002 & -0.003 \\
\hline 2 & $(9.9250,1.7501)$ & 10 & 8.499 & -8.503 & 6.962 & -6.965 & -0.001 & -0.002 \\
\hline 3 & $(9.4703,3.4469)$ & 20 & 7.330 & -7.333 & 6.643 & -6.646 & -0.001 & -0.003 \\
\hline 4 & $(8.7280,5.0391)$ & 30 & 6.338 & -6.341 & 6.122 & -6.125 & -0.001 & -0.002 \\
\hline 5 & $(7.7202,6.4781)$ & 40 & 5.436 & -5.439 & 5.415 & -5.418 & -0.001 & -0.002 \\
\hline 6 & $(6.4781,7.7202)$ & 50 & 4.561 & -4.564 & 4.544 & -4.547 & -0.001 & -0.002 \\
\hline 7 & $(5.0391,8.7280)$ & 60 & 3.659 & -3.662 & 3.534 & -3.537 & -0.001 & -0.003 \\
\hline 8 & $(3.4469,9.4703)$ & 70 & 2.667 & -2.670 & 2.417 & -2.420 & -0.001 & -0.003 \\
\hline 9 & $(1.7501,9.9250)$ & 80 & 1.497 & -1.501 & 1.226 & -1.230 & -0.001 & -0.002 \\
\hline 10 & $(0,10.0781)$ & 90 & -0.003 & -0.004 & -0.003 & -0.004 & -0.003 & -0.004 \\
\hline
\end{tabular}

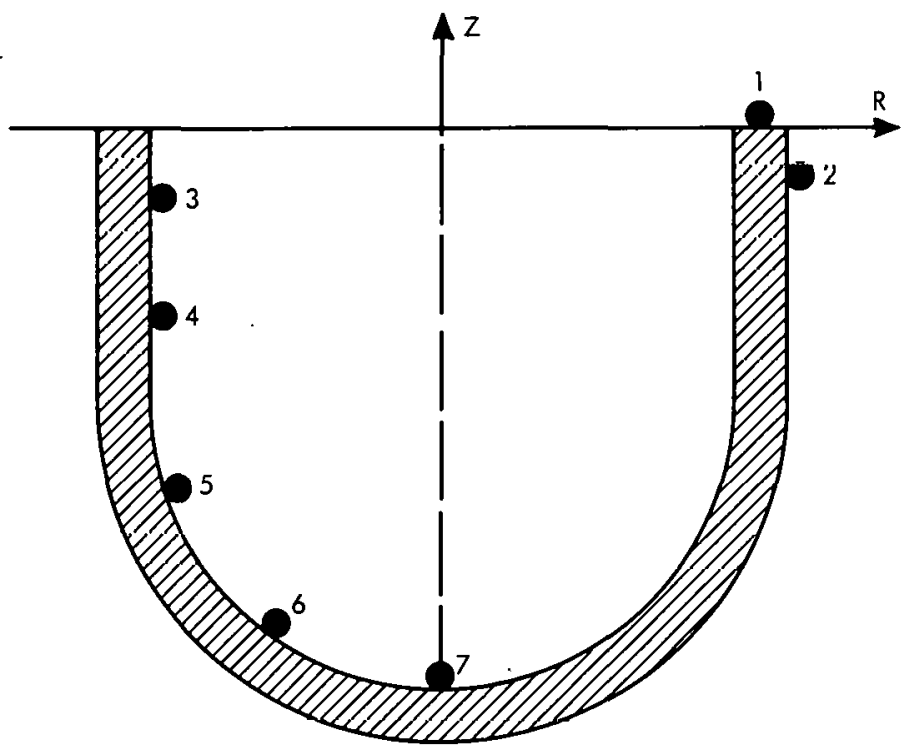

Figure 21. PART USED IN EXAMPLE FOR CASE 2. 
Table 2

COMPUTED OFF CENTER (CASE 2)

(X Offset (mils), 5.000; Y Offset (mils), 5.000; Z Offset (mils), 5.001;

Tilt (minutes), 1.4148 at 315.0-degree angle)

\begin{tabular}{|c|c|c|c|c|c|c|c|c|}
\hline \multirow{2}{*}{$\begin{array}{l}\text { Point } \\
\text { Number }\end{array}$} & \multirow{2}{*}{$\begin{array}{c}\text { Coordinates of } \\
\text { Ball Center } \\
\left(r_{1}, z_{1}\right)\end{array}$} & \multirow{2}{*}{$\begin{array}{c}\text { Normal } \\
\text { Angle } \\
\text { (degrees) }\end{array}$} & \multicolumn{2}{|c|}{$\begin{array}{c}\text { Measured Error } \\
\text { (mils) }\end{array}$} & \multicolumn{2}{|c|}{$\begin{array}{c}\text { Normal Error } \\
\quad(m i l s)\end{array}$} & \multicolumn{2}{|c|}{$\begin{array}{c}\text { Corrected Error } \\
\text { (mils) }\end{array}$} \\
\hline & & & Maximum & Minimum & Maximum & Minimum & $\overline{M a x i m u m}$ & Minimum \\
\hline 1 & $(10.5,0.0781)$ & 90 & 13.185 & 0.962 & 9.323 & 0.680 & 0.001 & -0.001 \\
\hline 2 & $(11.0781,-1.0)$ & 0 & 10.001 & -10.000 & 7.072 & -7.071 & 0.002 & -0.002 \\
\hline 3 & $(-9.9219,-2.0)$ & 0 & 10.000 & -10.000 & 7.071 & -7.071 & 0.003 & -0.002 \\
\hline 4 & $(-9.9219,-4.0)$ & 0 & 10.127 & -10.131 & 7.161 & -7.164 & 0.003 & -0.002 \\
\hline 5 & $(-8.5926,-9.9609)$ & 30 & 9.150 & -3.975 & 8.838 & -3.840 & 0.003 & -0.002 \\
\hline 6 & $(-4.9609,-13.5923)$ & 60 & 8.272 & 0.698 & 7.990 & 0.674 & 0.004 & -0.001 \\
\hline 7 & $(0,-14.9219)$ & 90 & 7.071 & 7.067 & 5.000 & 4.997 & -0.001 & -0.004 \\
\hline
\end{tabular}

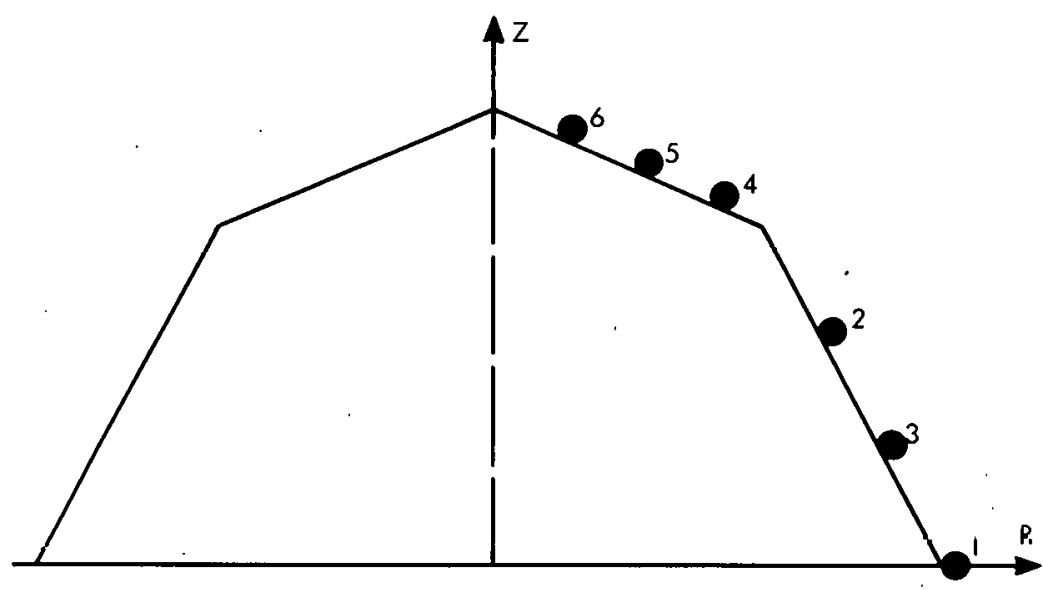

Figure 22. PART USED IN EXAMPLE FOR CASE 3.

Table 3 summarizes the results. Points 1 and 2 were used as the datum diameters.

Table 3

COMPUTED OFF CENTER (CASE 3)

(X Offset (mils), 5.000; Y Offset (mils), 5.000; Z Offset (mils), 5.001; Tilt (minutes), 1.4143 at 315.0-degree angle)

\begin{tabular}{|c|c|c|c|c|c|c|c|c|}
\hline \multirow{2}{*}{$\begin{array}{l}\text { Point } \\
\text { Number }\end{array}$} & \multirow{2}{*}{$\begin{array}{l}\text { Coordinates of } \\
\text { Ball Center } \\
\left(r_{1}, z_{1}\right)\end{array}$} & \multirow{2}{*}{$\begin{array}{l}\text { Normal } \\
\text { Angle } \\
\text { (degrees) }\end{array}$} & \multicolumn{2}{|c|}{$\begin{array}{l}\text { Meosured Error } \\
\text { (mils) }\end{array}$} & \multicolumn{2}{|c|}{$\begin{array}{c}\text { Normal Error } \\
\text { (mils) }\end{array}$} & \multicolumn{2}{|c|}{$\begin{array}{l}\text { Corrected Error } \\
\text { (mils) }\end{array}$} \\
\hline & & & Maximum & Minimum & Maximum & Minimum & Maximum & $\overline{\text { Minimum }}$ \\
\hline 1 & $(13.0741,0.0247)$ & 18.435 & 7.652 & -7.654 & 6.844 & -6.846 & 0.001 & -0.002 \\
\hline 2 & $(11.0741,6.0247)$ & 18.435 & 7.500 & -7.501 & 6.708 & -6.6709 & 0.001 & -0.003 \\
\hline 3 & $(12.0741,3.0247)$ & 18.435 & 7.499 & -7.500 & 6.707 & -6.708 & 0.001 & -0.002 \\
\hline 4 & $(8.0349,10.0699)$ & 63.435 & 3.525 & -3.526 & 3.344 & -3.345 & 0.002 & -0.001 \\
\hline 5 & $(6.0349,11.0699)$ & 63.435 & 3.334 & -3.334 & $3 . .163$ & -3.163 & 0.001 & -0.003 \\
\hline 6 & $(4.0349,12.0699)$ & 63.435 & 3.375 & -3.375 & 3.202 & -3.202 & 0.001 & -0.005 \\
\hline
\end{tabular}

